\title{
Multisensory integration in the dorsal cochlear nucleus: unit responses to acoustic and trigeminal ganglion stimulation
}

\author{
S. E. Shore \\ Kresge Hearing Research Institute and Department of Otolaryngology, University of Michigan, 1301 East Ann Street, Ann Arbor, MI \\ 48109, USA
}

Keywords: auditory, guinea pig, multisensory, neural pathways, somatosensory, trigeminal

\begin{abstract}
A necessary requirement for multisensory integration is the convergence of pathways from different senses. The dorsal cochlear nucleus (DCN) receives auditory input directly via the VIIIth nerve and somatosensory input indirectly from the Vth nerve via granule cells. Multisensory integration may occur in DCN cells that receive both trigeminal and auditory nerve input, such as the fusiform cell. We investigated trigeminal system influences on guinea pig DCN cells by stimulating the trigeminal ganglion while recording spontaneous and sound-driven activity from DCN neurons. A bipolar stimulating electrode was placed into the trigeminal ganglion of anesthetized guinea pigs using stereotaxic co-ordinates. Electrical stimuli were applied as bipolar pulses (100 $\mu$ s per phase) with amplitudes ranging from 10 to $100 \mu \mathrm{A}$. Responses from DCN units were obtained using a 16-channel, four-shank electrode. Current pulses were presented alone or preceding 100- or 200-ms broadband noise (BBN) bursts. Thirty percent of DCN units showed either excitatory, inhibitory or excitatory-inhibitory responses to trigeminal ganglion stimulation. When paired with BBN stimulation, trigeminal stimulation suppressed or facilitated the firing rate in response to BBN in $78 \%$ of units, reflecting multisensory integration. Pulses preceding the acoustic stimuli by as much as $95 \mathrm{~ms}$ were able to alter responses to BBN. Bimodal suppression may play a role in attenuating body-generated sounds, such as vocalization or respiration, whereas bimodal enhancement may serve to direct attention in low signal-to-noise environments.
\end{abstract}

\section{Introduction}

Multisensory integration is essential for achieving complex behaviors, yet relatively little research has focused on this intriguing capacity of neurons in the central nervous system. Multisensory integration has been defined as the non-linear integration of information from more than one modality that either enhances or depresses unit responses obtained in response to stimulation of one modality alone (Stein \& Meredith, 1990; Populin \& Yin, 2002; Brett-Green et al., 2003). Multisensory neurons have been identified in higher centres such as auditory cortex and superior colliculus (Stein \& Meredith, 1990; Populin \& Yin, 2002; Dehner et al., 2004) but few studies have described multisensory integration in lower auditory centres. Furthermore, most of the multisensory integration studied is that between visual and auditory or visual and somatosensory systems in central areas of the brain.

A requirement for multisensory integration is the convergence of pathways from more than one sense. The dorsal cochlear nucleus (DCN), in addition to receiving afferent connections from the VIIIth nerve, is innervated by higher auditory centres (Adams \& Warr, 1976; Covey et al., 1984; Spangler et al., 1987; Winter et al., 1989; Shore et al., 1991; Spangler \& Warr, 1991; Weedman \& Ryugo, 1996; Shore \& Moore, 1998; Schofield \& Cant, 1999) and also somatosensory neurons. The somatosensory projections originate in the trigeminal ganglion, interpolar and caudal spinal trigeminal nuclei and cuneate

Correspondence: Dr S. E. Shore, as above.

E-mail: sushore@umich.edu

Received 30 December 2004, revised 18 March 2005, accepted 29 March 2005 nuclei (Weinberg \& Rustioni, 1987; Wright \& Ryugo, 1996; Shore et al., 2003; Zhou \& Shore, 2004) and give rise to terminals that end in both the deep DCN and granule or marginal cell regions of the ventral cochlear nucleus (VCN) (Wright \& Ryugo, 1996; Shore et al., 2000; Zhou \& Shore, 2004). Stimulation of the dorsal column nuclei and manual manipulation of the pinna produce a complex pattern of inhibition and excitation of DCN neurons, which has been linked to processes contributing to sound localization in the cat (Young et al., 1995; Davis et al., 1996). DCN neurons can also be affected in a similar manner by stimulation of somatosensory nuclei innervating the vibrissae (Young et al., 1995) and peripheral nerves innervating the neck and forelimb (Kanold \& Young, 2001). Stimulation of the trigeminal ganglion, which innervates large regions of the face including vocal structures, primarily produces excitation of VCN neurons (Shore et al., 2003). A large percentage of the projections from the trigeminal ganglion, interpolar and caudal spinal trigeminal nuclei terminate on granule cells in the VCN and DCN (Shore et al., 2000; Zhou \& Shore, 2004), which ultimately affect the primary output neurons of the DCN (Young et al., 1995; Young, 1998). Thus, the anatomical substrates for multisensory integration in the DCN are in place and physiological studies indicate that the activity of DCN neurons can be influenced by both auditory and somatosensory stimulation. The question remains, however, as to whether DCN neurons combine the information from the two senses in a non-linear manner consistent with multisensory integration (Brett-Green et al., 2003). This study investigated the effects of both trigeminal ganglion and combined trigeminal-acoustic stimulation on responses of DCN neurons. 


\section{Materials and methods}

Experiments were performed on 20 healthy, female, adult pigmented guinea pigs (NIH outbred strain) with normal Preyer's reflexes, weighing 250-400 g. All procedures were performed in accordance with the NIH guidelines for the care and use of laboratory animals (NIH publication no. 80-23), guidelines provided by the University of Michigan (UCUCA) and Policies on the Use of Animals and Humans in Neuroscience Research approved by the Society for Neuroscience.

\section{Surgical preparation}

Guinea pigs were pre-medicated with a sympathetic blocking agent (Guanethedin, $30 \mathrm{mg} / \mathrm{kg}$; Sigma Chemical Co., St Louis, MO, USA) to reduce sympathetic vasoconstriction (Salar et al., 1992). The animals were anesthetized with ketamine $(120 \mathrm{mg} / \mathrm{kg})$ and Xylazine $(16 \mathrm{mg} / \mathrm{kg})$ and held in a stereotaxic device (Kopf) with hollow ear bars allowing for the delivery of sounds. In cases where trigeminal stimulation produced contractions of the jaw muscles, the animals were paralysed with Gallamine triethiodide $(3 \mathrm{mg} / \mathrm{h}$ i.p. $)$ and artificially respirated $(n=5)$. Anaesthesia was given at strict time intervals to insure deep level. Rectal temperature was monitored and maintained at $38 \pm 0.5{ }^{\circ} \mathrm{C}$ with a thermostatically controlled heating pad. The bone overlying the cerebellum and posterior occipital cortex was removed to allow visual placement of a recording electrode on the DCN, after aspirating a small amount of cerebellum to visualize its surface. The stimulating electrode was lowered into the ipsilateral trigeminal ganglion using stereotaxic coordinates $(0.37 \mathrm{~cm}$ caudal to bregma, $0.45 \mathrm{~cm}$ lateral from the midline and $1.35 \mathrm{~cm}$ ventral to bregma; Vass et al., 1998). Attempts were made to place the stimulating electrode in the ophthalmic division of the trigeminal ganglion previously found to project to the cochlear nucleus $(\mathrm{CN})$ (Shore et al., 2000). The stimulating electrode site was subsequently confirmed histologically (see below).

\section{Recordings}

All unit recordings were made in a sound-attenuating double-walled booth. Four-shank, 16-channel electrodes, fabricated by the University of Michigan Electrical Engineering and Computer Science Department, were used for recording unit responses, enabling us to record from many units simultaneously. The geometry of the recording sites is shown in Fig. 1A. The leftmost shank in the figure was positioned rostrally with the tips of the shanks inserted in a dorsal-to-ventral direction ending $0.5,1.0$ or $1.5 \mathrm{~mm}$ below the surface of the DCN. As the geometry and dimensions of the electrodes were known, we were able to determine the exact depth below the DCN surface for any recording site. The 16-channel multielectrode array was connected to a 16-channel amplifier via a signal input board which provided programmable gain, filtering (bandwidth $300-10 \mathrm{kHz}$ ) and analogto-digital conversion. Analog-to-digital conversion was performed by simultaneously sampling 12-bit converters at $40 \mathrm{kHz}$ per channel. Signals were then routed to multiple digital signal processor boards for computer-controlled spike waveform capture and sorting. The processor was controlled by a Pentium III $600 \mathrm{MHz}$, with $768 \mathrm{MB}$ RAM running under Windows NT, using a dual monitor display. The multichannel neuronal acquisition processor is designed to facilitate both waveform recording and spike sorting. Initially, the spike sorter was set to eliminate background noise. Unit waveforms were highlighted manually for capture. This included the waveforms generated by the artifact. Units were sorted using software (Plexon Corp.) both on- and offline depending on the experiment. It was often possible to sort waveforms from more than one unit per channel, thus increasing our yield of individually isolated units. In some cases it was not possible to sort spikes belonging to a single unit. In these cases, multi unit data are presented.

\section{Offline sorting and artifact removal}

Units on each channel were further sorted using principal component analysis offline (offline sorter; Plexon Corp.; cluster analysis). The artifact waveform was easily eliminated as a clearly separate cluster. In many cases, units were also separated into single units.

\section{Electrical stimuli}

Electrical pulses $(100 \mu \mathrm{s} /$ phase $)$, at intervals of $660 \mathrm{~ms}$, were presented either at the onset of the time window or with a delay of $25 \mathrm{~ms}$. A concentric, bipolar stimulating electrode was used to reduce current spread. Current amplitudes ranged from 10 to $100 \mu \mathrm{A}$. Spontaneous and activated firing were collected over a 200-ms window for 100 or 200 presentations.

\section{Acoustic stimuli}

Acoustic stimuli were delivered to the ears via Beyer dynamic earphones coupled to the hollow ear bars of a Kopf small animal stereotaxic device using TDT system II hardware for D/A conversion and analog attenuation. Digital signals were generated and delivered to the TDT hardware by a Pentium PC using the TDT software package SigPlay32. Stimuli were generated using a sample rate of $100 \mathrm{kHz}$ at 16-bit resolution. The stimulus variable sequences in pseudo-random order were generated from within MATLAB. The frequency response of the stimulus system was assessed by measuring phase and magnitude response to known stimuli in a closed loop with a known reference microphone. Equalization to correct for the system response was performed on the digital waveforms in the frequency domain. Gain for noise stimuli was adjusted such that tone and noise signals had equivalent energy. The calibrated response was flat from $100 \mathrm{~Hz}$ to $24 \mathrm{kHz}$.

\section{Unit typing}

Units were isolated using principal component analysis before classification. To identify unit types, acoustic stimuli consisted of 50 -ms tone bursts, with $1.5-\mathrm{ms}$ rise-fall times, at unit best frequency $(\mathrm{BF})$, as well as $50-\mathrm{ms}$ broadband noise $(\mathrm{BBN})$ bursts $(5 / \mathrm{s})$. The shape of the stimulus gate was cosine. Units were classified on the basis of their post-stimulus time histogram (PSTH) shapes generated in response to the $\mathrm{BF}$ tone bursts at $20 \mathrm{~dB}$ sensation level and ratelevel functions for BF tone bursts and noise bursts (Godfrey et al., 1975a,b; Rhode \& Smith, 1986; Stabler et al., 1996; Young, 1998). Response areas, inter-spike interval histograms and regularity analyses assisted in the classification. Responses to BBN were considered to be normal if the distribution of thresholds across the array ranged from approximately 10 to $30 \mathrm{~dB}$ SPL. This threshold range has been previously established to correspond to normal compound action potential (CAP) thresholds of 30, 20 and $10 \mathrm{~dB} \mathrm{SPL}$ at 2, 6 and $18 \mathrm{kHz}$ tonebursts, respectively (Le Prell et al., 2003; Shore et al., 2003).

\section{Multisensory integration}

For assessing integration of acoustic and trigeminal information, trigeminal stimuli were electrical stimuli to the trigeminal ganglion, as described above, and acoustic stimuli were 100-ms BBN bursts. Trigeminal stimuli preceded the noise bursts by specified gaps $(\delta \mathrm{t})$ in order to determine the degree and time-course of multisensory 
integration. To test for bimodal enhancement or suppression, the formula developed by Populin \& Yin (2002) was adapted as follows:

$$
B E=[(B i-T-A) /(T+A)] \times 100
$$

where $B E$ is percentage value of bimodal enhancement, $B i$ is bimodal response, $T$ is trigeminal response and $A$ is auditory response expressed as number of spikes computed over a 100-ms window beginning at the onset of auditory stimulation.

Bimodal suppression was calculated as follows:

$$
B S=\left[\left(B i-U n i_{\max }\right) / U n i_{\max }\right] \times 100
$$

where $B i$ is bimodal response and $U n i_{\max }$ is the larger of the unimodal responses. Bimodal suppression occurs when $B S<0$.

In many cases, the responses to bimodal stimulation resulted in an alteration of the temporal nature of the response. This feature is being explored in a separate study (S.E. Shore and P. Manis, unpublished results). Noise stimulation was used in this study because the majority of units recorded on 16 channels responded to the noise regardless of their BFs. Thus, it was possible to assess the responses of a large number of neurons to both the trigeminal and sound stimulation.

The data analysis was performed using a custom toolbox in MATLAB both during and after the experiments. This system generated
PSTHs, rate-level functions and thresholds. A response threshold was taken to be the (linearly interpolated) sound level at which difference in the mean spike rate between the driven response and the spontaneous activity satisfied a Student's $t$-test for statistical significance at a level of $P<0.01$. This algorithm gave reliable thresholds that agreed closely with visual inspection of PSTHs and rate-level functions.

\section{Histology}

To mark electrode tracks, the recording and stimulating electrodes were dipped in 1,1-dioctadecyl-3,3,3',3'- tetramethyllindocarbocyanine perchlorate $(10 \%$; Molecular Probes) or fluorgold $(2 \%)$ before being inserted into the brain. At the end of each experiment, the animal was perfused transcardially with $4 \%$ paraformaldehyde. The brain and left trigeminal ganglion were removed from the skull and immersed in 20\% sucrose solution (Shore et al., 1992; Shore \& Moore, 1998). The following day, the brain and trigeminal ganglion were cryosectioned at $40-60 \mu \mathrm{m}$, placed on slides and examined under epifluorescence for evidence of recording and stimulating electrode locations. The locations of the electrode within the ganglion varied from 440 to $1080 \mu \mathrm{m}$ in depth from the surface and were most often located in the ophthalmic division (16 of 20) although occasionally located in the other two divisions (four of 20).

\section{A}
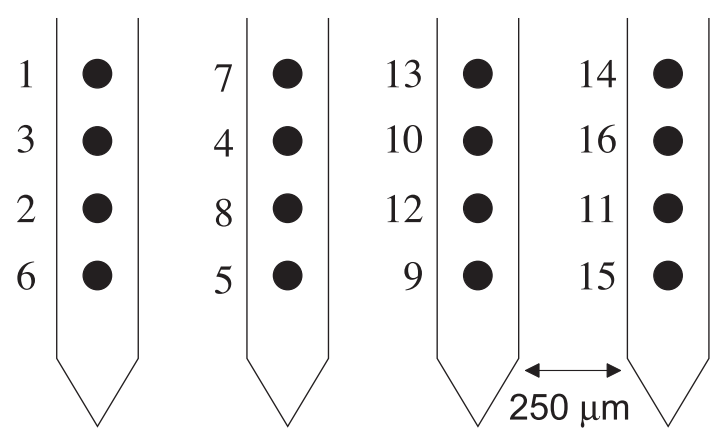

Dorsal

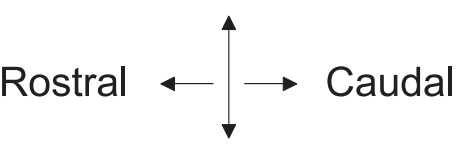

Ventral
B
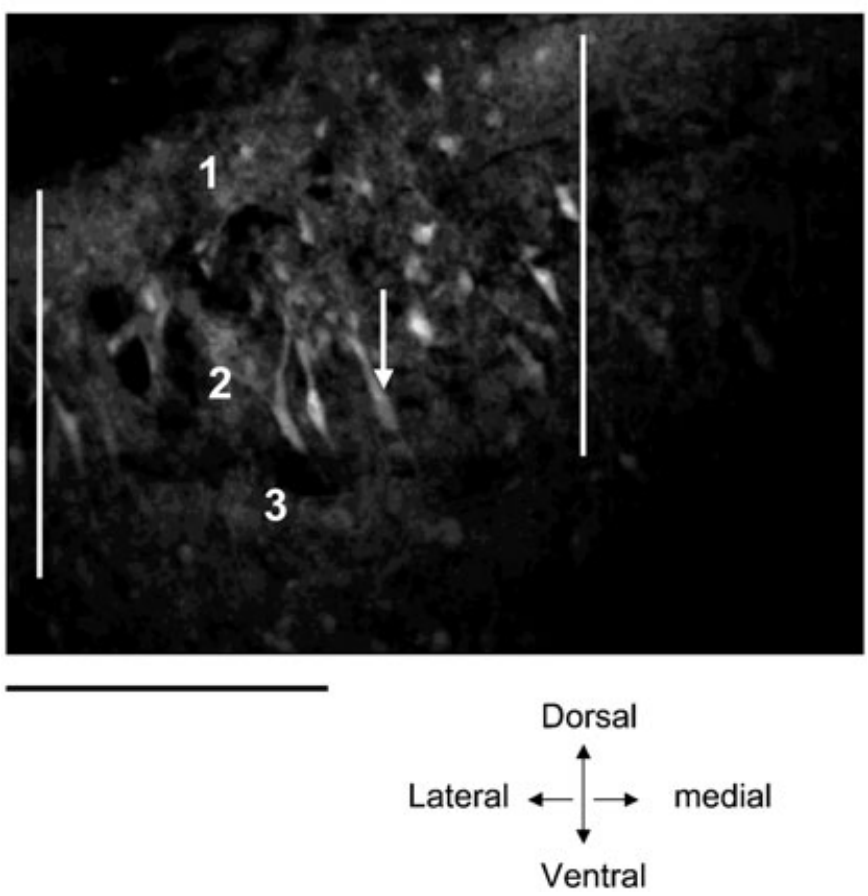

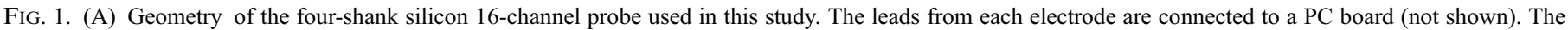

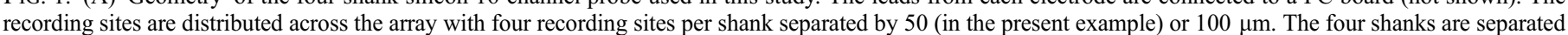

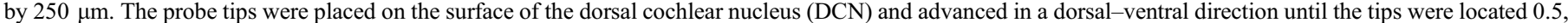

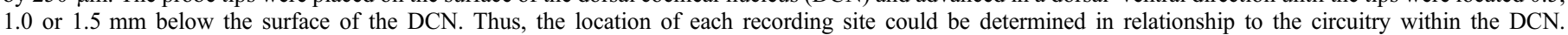

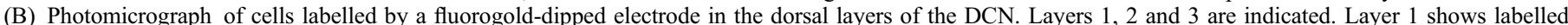

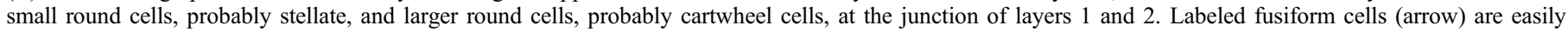

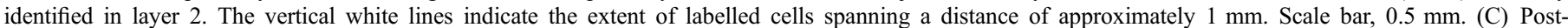

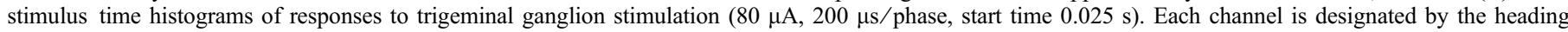

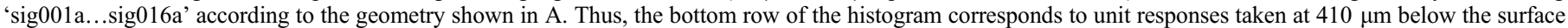

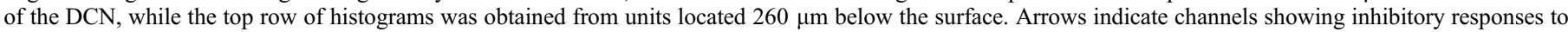

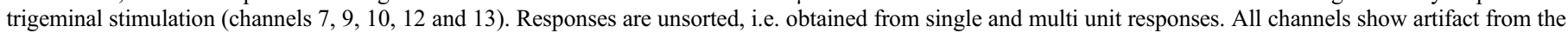
electrical stimulation at around $26 \mathrm{~ms}$. Bin width, $0.5 \mathrm{~ms} ; 100$ presentations. 
C
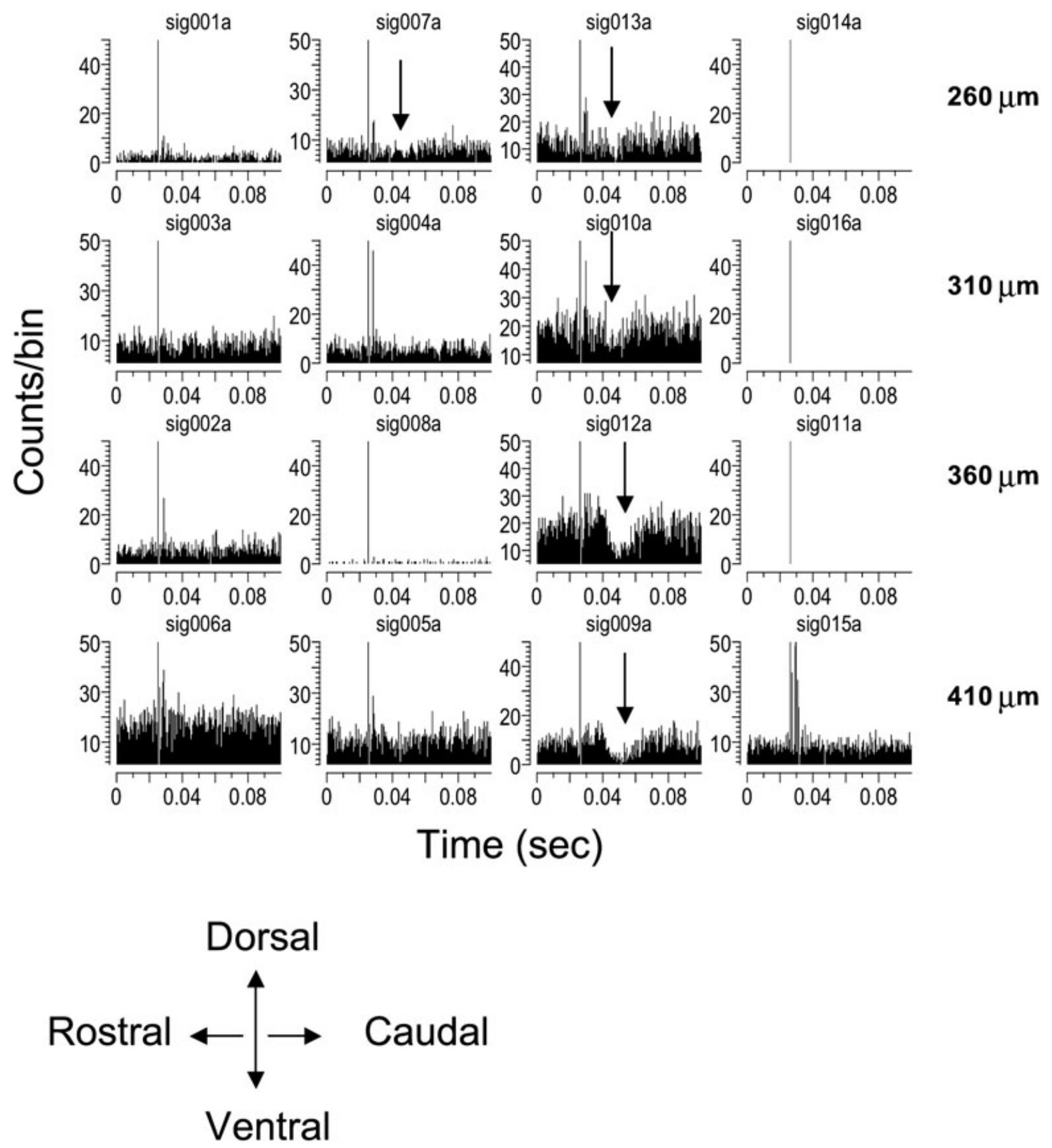

FIG. 1. Continued

Results

Results are based on responses from 445 units in 20 guinea pigs. Responses were sorted using principal component analysis (offline sorter; Plexon Corp.) to isolate single units. Of the sorted responses 248 units were single units $(56 \%$, see Table 1$)$. Population or mean data are presented as multi plus single unit. Multisensory integration data are shown only for isolated single units in six of the 20 animals. For these single units, responses to BF tone bursts and noise stimuli determined their unit type (see Materials and methods). 
TABLE 1. Numbers of units recorded in 20 animals and their responses to trigeminal stimulation in the absence of sound

\begin{tabular}{|c|c|c|c|c|c|c|c|c|c|c|c|c|}
\hline \multirow{2}{*}{$\begin{array}{l}\text { Experiment date* } \\
(\mathrm{d} / \mathrm{m} / \mathrm{y})\end{array}$} & \multicolumn{4}{|c|}{ Single units } & \multicolumn{4}{|c|}{ Multi-unit recordings } & \multicolumn{4}{|c|}{ Combined single and multi-units } \\
\hline & Total & In & $\mathrm{E}$ & E/In & Total & In & $\mathrm{E}$ & $\mathrm{E} / \mathrm{In}$ & Total & In & $\mathrm{E}$ & $\mathrm{E} / \mathrm{In}$ \\
\hline $5 / 9 / 2002$ & 5 & 1 & - & 1 & 12 & 3 & - & 1 & 17 & 4 & 0 & 2 \\
\hline $27 / 2 / 2003$ & 10 & 3 & - & - & 15 & 1 & - & - & 25 & 4 & - & - \\
\hline $13 / 3 / 2003 a$ & - & - & - & - & 16 & - & 3 & 6 & 16 & 0 & 3 & 6 \\
\hline $13 / 3 / 2003 b$ & 6 & - & 1 & 3 & 14 & - & 7 & 2 & 20 & 0 & 8 & 5 \\
\hline $20 / 3 / 2003$ & 21 & - & - & 2 & 15 & - & 1 & 1 & 36 & 0 & 1 & 3 \\
\hline $27 / 3 / 2003$ & 18 & 1 & - & 1 & 10 & - & - & 1 & 28 & 1 & 0 & 2 \\
\hline $1 / 5 / 2003$ & 25 & 1 & 1 & - & 10 & - & 1 & 2 & 35 & 1 & 2 & 2 \\
\hline $17 / 7 / 2003$ & 4 & 1 & - & - & 14 & 4 & - & - & 18 & 5 & 0 & 0 \\
\hline $24 / 7 / 2003$ & 10 & 1 & 1 & 2 & 10 & 1 & 2 & 1 & 20 & 2 & 3 & 3 \\
\hline $18 / 9 / 2003$ & 19 & 2 & 1 & - & 1 & - & - & - & 20 & 2 & 1 & - \\
\hline $30 / 9 / 2003$ & 17 & 1 & 1 & 2 & 3 & - & - & 1 & 20 & 1 & 1 & 3 \\
\hline $3 / 12 / 2003$ & - & - & - & - & 16 & 6 & 1 & - & 16 & 6 & 1 & 0 \\
\hline $7 / 1 / 2004$ & 18 & 5 & - & - & 1 & - & - & - & 19 & 5 & 0 & 0 \\
\hline $15 / 1 / 2004$ & 13 & - & - & - & 3 & - & 1 & - & 16 & 0 & 1 & 0 \\
\hline $21 / 1 / 2004$ & 21 & - & - & 3 & 1 & - & - & - & 22 & - & - & 3 \\
\hline $28 / 1 / 2004$ & 4 & - & - & 1 & 10 & - & 2 & 1 & 14 & 0 & 2 & 2 \\
\hline $18 / 3 / 2004$ & 4 & - & - & - & 16 & - & 8 & 3 & 20 & 0 & 8 & 3 \\
\hline $25 / 3 / 2004$ & 4 & - & 2 & - & 6 & - & 1 & - & 10 & 0 & 3 & 0 \\
\hline $28 / 4 / 2004$ & 8 & 1 & 1 & 6 & 8 & - & - & 3 & 16 & 1 & 1 & 9 \\
\hline $27 / 5 / 2004$ & 3 & - & - & - & 15 & 2 & 1 & 4 & 18 & 2 & 1 & 4 \\
\hline $28 / 10 / 2004 a$ & 17 & 2 & 8 & - & 1 & - & 1 & - & 18 & 2 & 9 & 0 \\
\hline $28 / 10 / 2004 b$ & 21 & 1 & 12 & 2 & - & - & - & - & 21 & 1 & 12 & 2 \\
\hline Totals $(n)$ & 248 & 20 & 28 & 23 & 197 & 17 & 29 & 26 & 445 & 37 & 57 & 49 \\
\hline Responsive (\%) & 29 & 8.1 & 11.3 & 9.3 & 33.8 & 5.9 & 14.7 & 13.2 & 32.1 & 8.3 & 12.8 & 11 \\
\hline
\end{tabular}

The bottom line indicates that $29 \%$ of all single units showed a response to trigeminal stimulation in the absence of sound. This increased to $34 \%$ for multi units and was $32 \%$ when single and multi units were counted together. the number of single and multi units, showing excitatory (E), excitatory followed by an inhibitory phase (E/In) or inhibitory (In) responses to. The percentages of units showing In, E or E/In responses were similar for single and multi-unit recordings. *First and second penetrations are indicated by a and $b$, respectively.

Figure 1A shows the geometric configuration of the four-shank recording electrode. The electrode was inserted into the DCN (Fig. 1B) so that the tips were located $0.5,1.0$ or $1.5 \mathrm{~mm}$ ventral to its surface, enabling calculation of the exact dorsal-ventral location of each recording site. The recording sites were separated by 50 or $100 \mu \mathrm{m}$ and each shank was separated by $250 \mu \mathrm{m}$. Figure $1 \mathrm{C}$ shows PSTHs of multi unit responses recorded from the 16 channels in one animal after trigeminal ganglion stimulation $(90 \mu \mathrm{A}, 200 \mu \mathrm{s} /$ phase, 100 presentations). The channels are delineated as 'sig001...sig016', indicating the location of each channel according to the geometry shown in Fig. 1A. In this example, trigeminal stimulation produced inhibitory responses on channels 7, 9, 10, 12 and 13 (indicated by arrows). The other channels showed no response to trigeminal stimulation and thus represent the spontaneous rates of these units.

\section{Trigeminal ganglion stimulation elicits inhibitory, excitatory and excitatory-inhibitory responses in dorsal cochlear nucleus units}

Approximately $30 \%$ of DCN units tested responded to trigeminal ganglion stimulation in the absence of sound stimulation (Table 1). Responses could be exclusively inhibitory (In), with responses often lasting up to $70 \mathrm{~ms}$ (Fig. 2A). This type of inhibition occurred without preceding excitation. Responses could also be exclusively excitatory (E; Fig. 2B) or excitatory followed by an inhibitory phase (E/In; Fig. 2C). Table 1 shows the number of units responding to trigeminal ganglion stimulation in the absence of sound. Of $32 \%$ of units responding to trigeminal stimulation (single plus multi units) $8 \%$ showed In responses, $13 \%$ showed E responses and 11\% showed E/In responses. The distribution of response type remained the same, whether the responses were from single or multi units. The inhibition in E/In units could also be fairly long in duration (approximately $50 \mathrm{~ms}$ ), as shown in Fig. 2C.

Units that responded to trigeminal ganglion stimulation showed a wide range $(20-100 \mu \mathrm{A})$ in the distribution of stimulation thresholds (Fig. 3). The mean thresholds for In, E and E/In units were similar (Fig. 3B). Thresholds depended on the location of the stimulating electrode, with lowest thresholds occurring when the electrode was in the ophthalmic division of the trigeminal ganglion (data not shown).

Units exhibiting inhibition alone (In units) tended to be located within the first $0.5 \mathrm{~mm}$ from the DCN surface. In contrast, units exhibiting excitation or excitation and inhibition (E and $\mathrm{E} / \mathrm{in})$ tended to be located throughout the DCN (Fig. 3A). The response latencies to electrical stimulation ranged from 5 to $30 \mathrm{~ms}$ (Fig. 4A) and were significantly longer, by approximately $3 \mathrm{~ms}$, for In units than for $\mathrm{E}$ and E/In units (Fig. 4B) as indicated by a Student's $t$-test of statistical significance $(P<0.001)$.

\section{Dorsal cochlear nucleus neurons integrate acoustic and somatosensory stimuli}

Responses to bimodal stimulation were collected from six of the 20 animals used in this study. To avoid ambiguity in the results, only sorted, single units were assessed for multisensory integration. Figures 5 and 6 outline the procedures used for unit sorting and typing. Figure 6 shows a typical response for a 'buildup' unit as represented by a PSTH to $\mathrm{BF}$ tones and rate level functions for BF tones and noise.

Multisensory integration is defined in this study as 'bimodal enhancement' if the bimodal responses exceeded the sum of the 


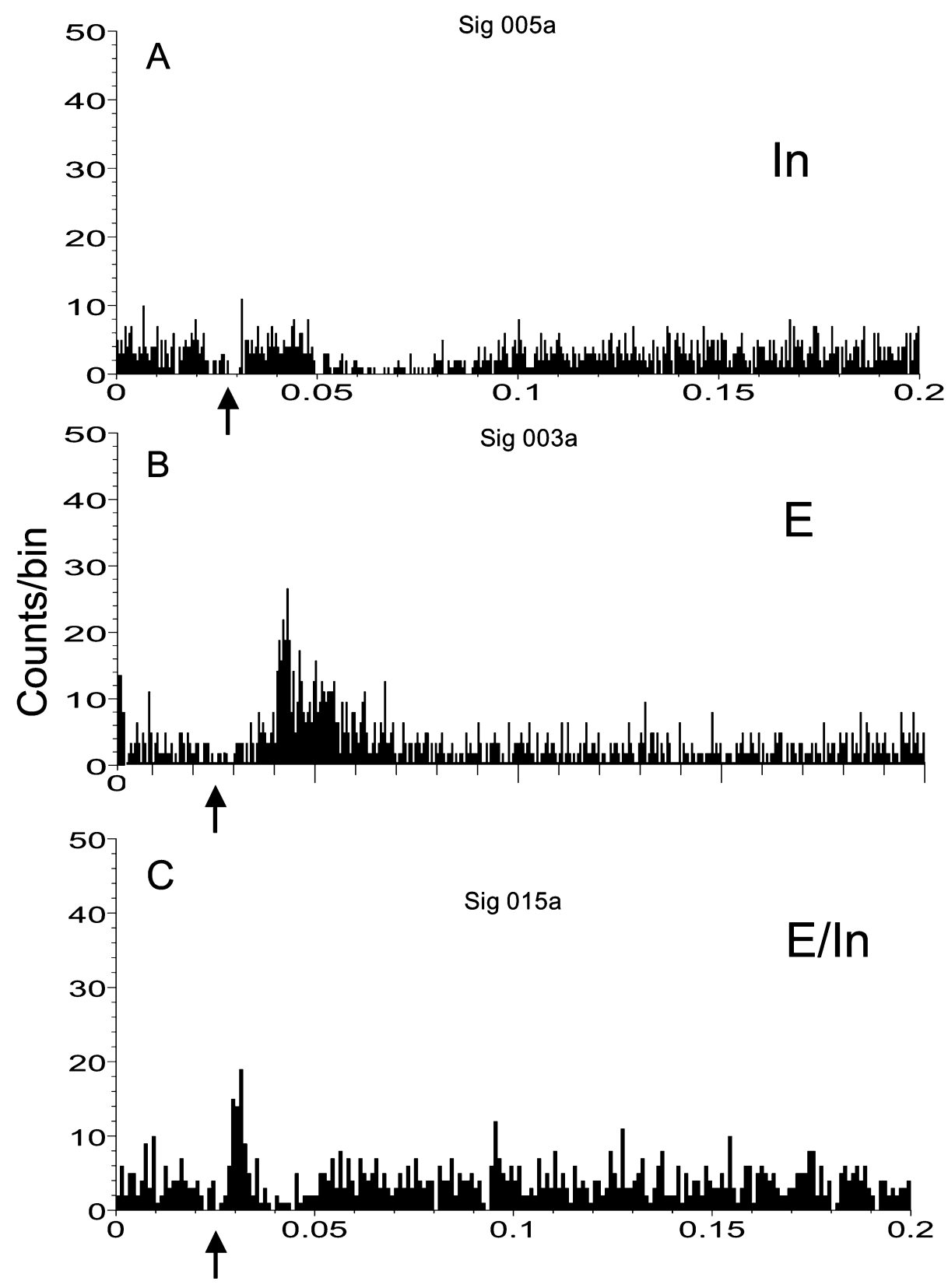

FIG. 2. Trigeminal ganglion stimulation elicits inhibitory (In), excitatory (E) and excitatory-inhibitory (E/In) responses of dorsal cochlear nucleus units. (A) Poststimulus time histogram (PSTH) for In type response. Arrow indicates stimulus onset. Inhibition occurs with a latency around $20 \mathrm{~ms}$ and lasts for approximately $70 \mathrm{~ms}$. (B) PSTH for E type response, which occurs with a latency of approximately $15 \mathrm{~ms}$ and lasts for around $25 \mathrm{~ms}$, returning to the pre-stimulation spike rate. (C) PSTH for E/In type response. Excitation with a shorter latency than B is followed by inhibition that recovers after approximately $20 \mathrm{~ms}$. Current level, $80 \mu \mathrm{A}$; bin width, $1 \mathrm{~ms} ; 200$ presentations. Responses are from sorted single units.

individual unimodal responses and 'bimodal suppression' when the bimodal response was less than the larger of the unimodal responses (after Populin \& Yin, 2002). The bimodal enhancement and suppression data are summarized in Table 2. Of 115 single units tested with bimodal stimulation, in which the trigeminal stimulus preceded the acoustic stimulus, 90 (78\%) showed multisensory integration when measured during the first half of the acoustic stimulus. The percentage decreased to $72 \%$ when integration was measured during the second half of the response to the BBN stimulus. The number of units showing integration was greatest when $\delta$ t was $20 \mathrm{~ms}(88 \%)$ and decreased for $\delta \mathrm{t}$ of $95 \mathrm{~ms}(65 \%)$. Individual examples of bimodal suppression and enhancement are shown below.
Trigeminal ganglion stimulation can suppress dorsal cochlear nucleus responses to sound (bimodal suppression)

When preceded by acoustic stimulation, trigeminal stimulation could dramatically suppress the firing rate evoked by the sound alone (bimodal suppression). Sixty percent (69 of 115) of the single units tested showed bimodal suppression during the first half of the BBN response and 44\% (51 of 115) during the second half (Table 2). Figure 7 shows PSTHs from one unit to BBN stimulation (Fig. 7A) and combined trigeminal-BBN stimulation (Fig. 7B). A strong suppression of the firing rate to the noise burst occurs when it is preceded by trigeminal stimulation (Fig. 7B). This suppression is quantified 
A

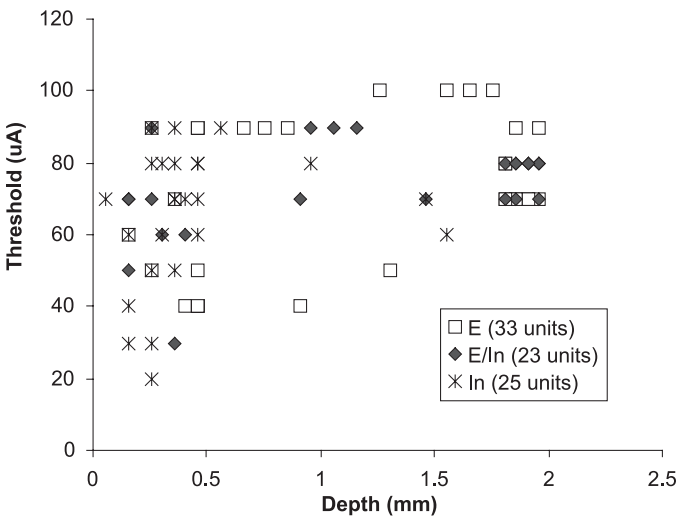

B

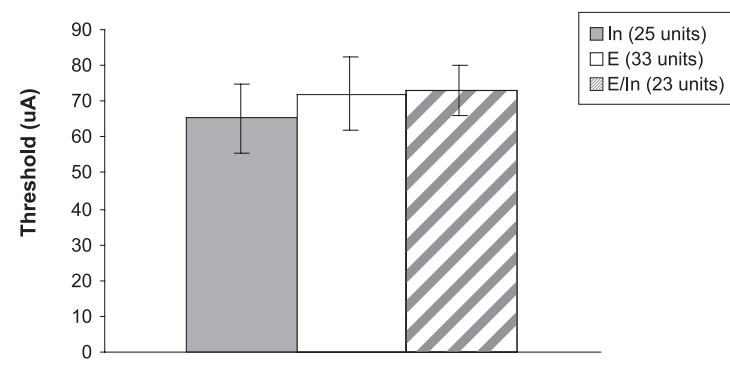

FIG. 3. Dorsal cochlear nucleus neurons show varied thresholds to trigeminal ganglion stimulation. (A) Scatter plot shows inhibitory (In), excitatory (E) and excitatory-inhibitory $(\mathrm{E} / \mathrm{In})$ response thresholds from 81 units to electrical stimulation at $80 \mu \mathrm{A}$. Thirty-one percent of units responding to trigeminal ganglion stimulation showed inhibition (In), 41\% showed excitation alone (E) and $28 \%$ showed excitation followed by inhibition (E/In). (B) Mean thresholds of In, E and E/In responses indicate similar thresholds for each type of response. Single and multi units combined.

(see Materials and methods for formulas) as a negative percentage shown in Fig. 7B. Suppression measured during the first half $(100-150 \mathrm{~ms})$ of the acoustic stimulus was similar to that measured in the second half $(150-200 \mathrm{~ms})$ in this unit indicating a constant suppression over the duration of the noise burst. However, suppression could also be delayed, as shown in Fig. 8. The firing rate elicited by the noise burst alone (Fig. 8A) is suppressed more significantly during the second half of the noise burst (150-200 ms; Fig. 8B).

Trigeminal ganglion stimulation can enhance dorsal cochlear nucleus responses to sound (bimodal enhancement)

In other cases, the addition of a trigeminal stimulus could enhance the firing rate to a sound. Eighteen percent (21of 115) of single units showed bimodal enhancement during the first half of the BBN response and 28\% (32 of 115) during the second half (see Table 2). Figure 9 shows an example of bimodal enhancement in one unit. The firing rate evoked by the acoustic stimulus (Fig. 9A) is enhanced by $199 \%$ during the first half and by $91 \%$ during the second half of the noise stimulus (Fig. 9B). In another unit (Fig. 10), the enhancement occurs only during the second half of the noise stimulus (Fig. 10B). There is, in fact, some suppression of activity during the first half of the stimulus when it is preceded by trigeminal stimulation (Fig. 10B). This has the effect of producing a response with a temporal pattern that is the inverse of the response evoked by the noise stimulus alone.
A

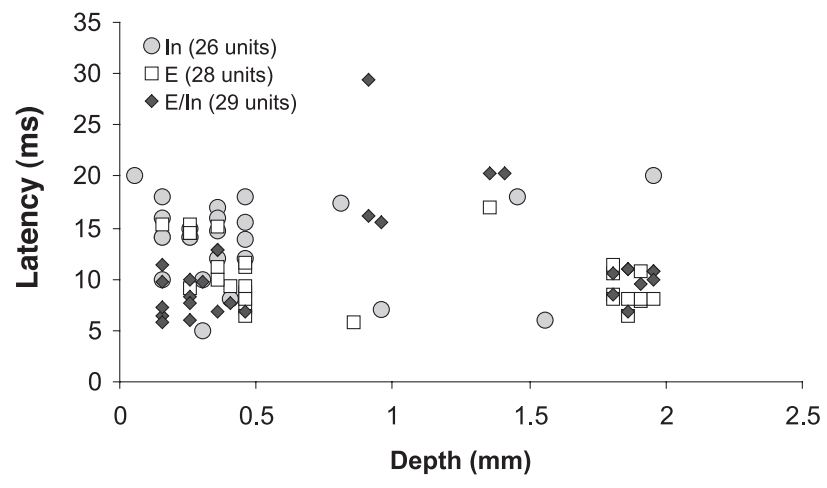

B

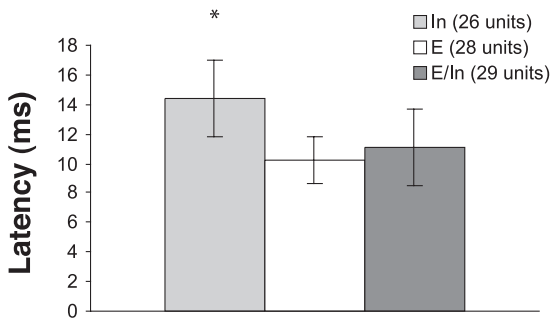

FIG. 4. Dorsal cochlear nucleus neurons have a wide range of response latencies to trigeminal ganglion stimulation. (A) Scatter plot shows response latencies from 96 units to electrical stimulation at $80 \mu \mathrm{A}$. (B) Mean latencies of responses to trigeminal stimulation at $80 \mu \mathrm{A}$. Latencies for inhibitory (In) responses are significantly longer $(P<0.001)$ than excitation alone $(\mathrm{E})$ and excitation followed by inhibition $(\mathrm{E} / \mathrm{In})$ responses. Single and multi units combined.

Trigeminal input induces long-duration suppression/enhancement of acoustic responses

The multisensory integration demonstrated above was also apparent when there was a temporal offset larger than $5 \mathrm{~ms}$ between the trigeminal and the acoustic stimulus. The effects of trigeminal stimulation could last up to $95 \mathrm{~ms}$ (see Table 2). In Fig. 11, the response evoked to a low-level BBN stimulus was greatly reduced by preceding the noise stimulus with a trigeminal stimulus by $60 \mathrm{~ms}$, indicating a long-lasting bimodal suppression. The firing rate was further suppressed as the $\delta \mathrm{t}$ decreased to $20 \mathrm{~ms}$.

\section{What type of dorsal cochlear nucleus unit shows multisensory integration?}

Figure $12 \mathrm{~A}$ shows multisensory integration in single units as a function of their location in the DCN. Integration is expressed as a negative percentage if bimodal suppression occurred or a positive percentage if bimodal enhancement occurred. Symbols designate the $\delta$ t and time segment across which integration was measured. Units located within $0.5 \mathrm{~mm}$ of the DCN surface showed greater bimodal enhancement and suppression than units located deeper than $0.5 \mathrm{~mm}$. Figure 12B shows the same units as in Fig. 12A typed according to their responses to $\mathrm{BF}$ tone bursts and noise.

The majority of single units integrating trigeminal and acoustic information showed buildup or pauser-buildup responses to BF tone burst stimulation (Fig. 12B), although other unit types, such as onset and primary-like units, also demonstrated multisensory integration. Buildup and pauser-buildup units were especially predominant in the 
A

B
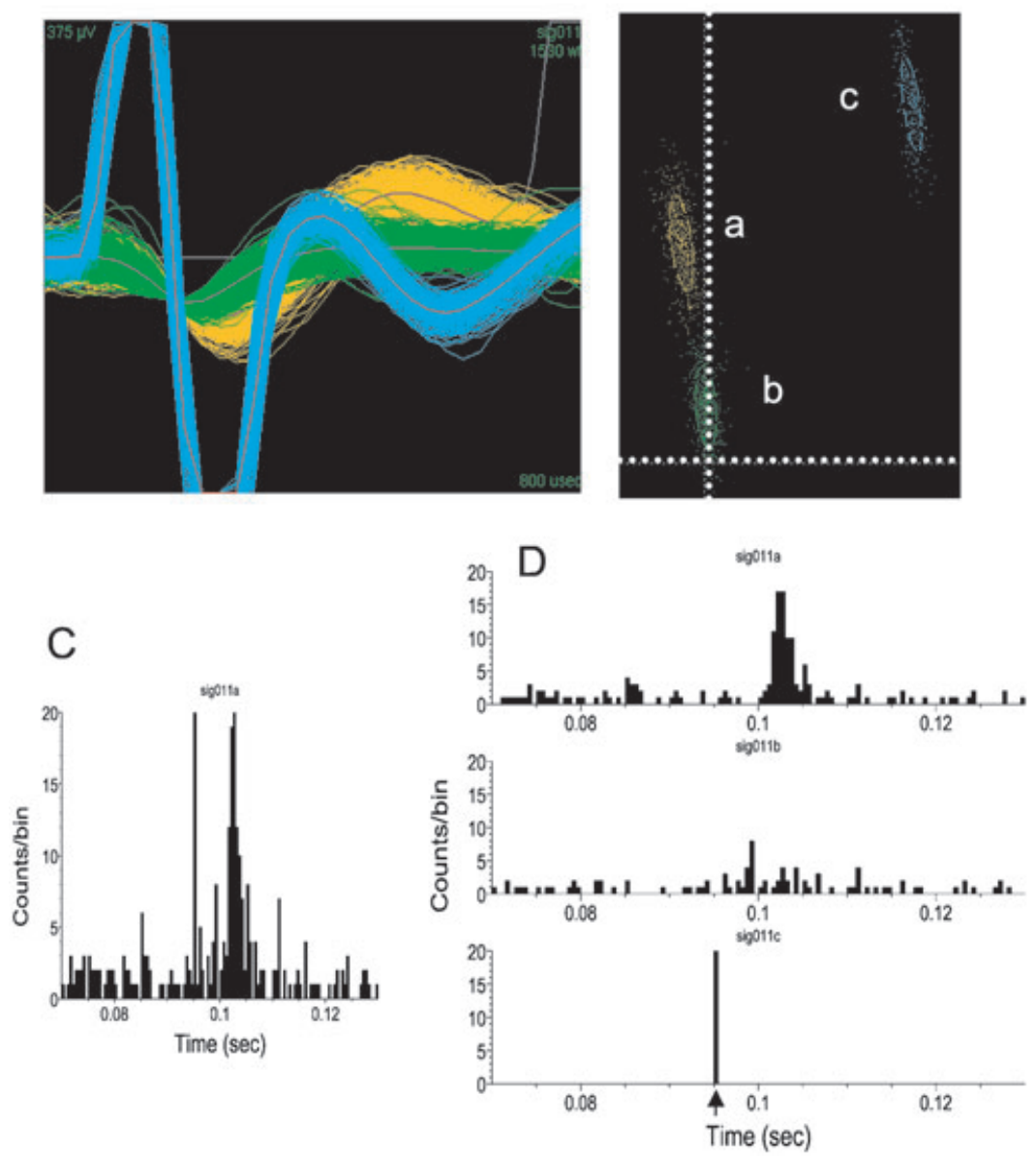

FIG. 5. Principal component analysis is used to separate multi unit responses. Waveforms (A) and principal component clusters (B) demonstrate three waveforms $(\mathrm{a}-\mathrm{c})$. Waveforms $\mathrm{a}$ and $\mathrm{b}$ are single units and waveform $\mathrm{c}$ is stimulus artifact. Post-stimulus time histogram (PSTH) representing the composite (multi-unit) response on channel 11 to trigeminal stimulation is shown in C. Responses to each component (single unit) are shown in PSTHs in D. Lower histogram shows stimulus artifact (sig011c); middle and top histograms show responses from the two, individual single units separated by the offline sorter (sig011a and b). Trigeminal stimulation is at $80 \mu \mathrm{A}$ (indicated by arrow), 200 presentations. Bin width, $0.5 \mathrm{~ms}$.

TABLE 2. Number of single units in six animals demonstrating bimodal suppression or enhancement (multisensory integration) when trigeminal stimulation preceded broadband noise $(\mathrm{BBN})$ presentation

\begin{tabular}{|c|c|c|c|c|c|c|}
\hline \multirow{2}{*}{$\begin{array}{l}\text { Experiment date* } \\
(\mathrm{d} / \mathrm{m} / \mathrm{y})\end{array}$} & \multirow[b]{2}{*}{$\delta \mathrm{t}(\mathrm{ms})$} & \multirow[b]{2}{*}{ Number of units } & \multicolumn{2}{|c|}{ Latency of $100-150 \mathrm{~ms}$} & \multicolumn{2}{|c|}{ Latency of $150-200 \mathrm{~ms}$} \\
\hline & & & Suppression & Enhancement & Suppression & Enhancement \\
\hline $7 / 1 / 2004$ & 5 & 17 & 16 & 0 & 6 & 2 \\
\hline $15 / 1 / 2004$ & 5 & 13 & 9 & 1 & 3 & 4 \\
\hline $21 / 1 / 2004$ & 5 & 16 & 3 & 13 & 3 & 12 \\
\hline $28 / 10 / 04 a$ & 5 & 17 & 6 & 0 & 8 & 2 \\
\hline $28 / 10 / 04 b$ & 5 & 18 & 11 & 1 & 7 & 5 \\
\hline $18 / 9 / 2003$ & 20 & 17 & 14 & 2 & 14 & 2 \\
\hline $30 / 9 / 2003$ & 20 & 17 & 10 & 4 & 10 & 5 \\
\hline Totals $(n)$ & - & 115 & 69 & 21 & 51 & 32 \\
\hline Responsive (\%) & - & & 60 & 18 & 44 & 28 \\
\hline $18 / 9 / 2003$ & 95 & 17 & 6 & 6 & 5 & 10 \\
\hline $30 / 9 / 2003$ & 95 & 17 & 9 & 1 & 6 & 2 \\
\hline
\end{tabular}

Calculations are made for two time periods (100-150 and 150-200 ms) during the response to the BBN stimulus. Three $\delta \mathrm{t}$ values (5, 20 and $95 \mathrm{~ms})$ are shown. As the 20- and $95-\mathrm{ms} \mathrm{dt}$ conditions were tested in the same units, the $95-\mathrm{ms} \mathrm{dt}$ condition is excluded from the total. Up to $78 \%$ of units showed multisensory integration, depending on the time period measured. During the first half of the BBN, $60 \%$ showed suppression and $18 \%$ enhancement. During the second half of the BBN $44 \%$ showed suppression and $28 \%$ enhancement. *First and second penetrations are indicated by a and b, respectively. 

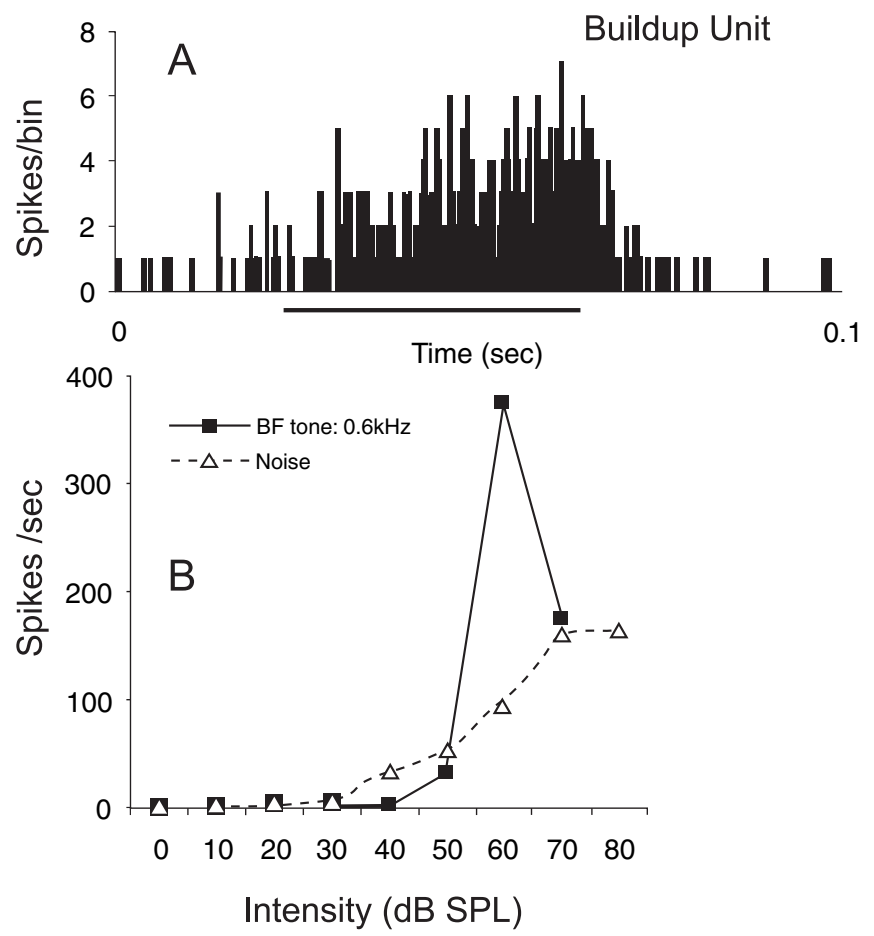

FIG. 6. Unit typing is determined by obtaining single unit (as determined in Fig. 5) responses to $50-\mathrm{ms}$ best frequency (BF) tonebursts and $50-\mathrm{ms}$ broadband noise (BBN) bursts. (A) Post-stimulus time histogram (PSTH) from one unit (BF, $-0.6 \mathrm{kHz} ; 20 \mathrm{~dB}$ sensation level; bin width, $0.5 \mathrm{~ms}$ ). Bar below graph indicates onset and duration of toneburst. (B) Rate level functions for the same unit to the BF toneburst and 50-ms BBN burst. The unit shown here was determined to be a buildup unit based on its PSTH shape and type IV rate level function.

top $0.4 \mathrm{~mm}$ of the DCN, consistent with the location of fusiform (also called pyramidal) cells in layer 2 of the DCN (Hackney et al., 1990).

\section{Discussion}

\section{Excitatory, inhibitory and complex responses to trigeminal ganglion stimulation}

Approximately $30 \%$ of DCN units tested responded to trigeminal ganglion stimulation in the absence of acoustic stimulation. Single and multi unit data showed the same trends. Thresholds of responses were lowest when the stimulating electrode was located in the ophthalmic and a portion of the mandibular divisions of the trigeminal ganglion, shown previously to send projections to the CN (Shore et al., 2000).

Responses in the absence of sound were most often excitatory (E; $39 \%$ ) but could also be excitatory followed by an inhibitory phase (E/In; $32 \%$ ) or just inhibitory (In; $28 \%$ ). The In responses tended to be recorded from locations less than $500 \mu \mathrm{m}$ from the surface of DCN, whereas the $\mathrm{E}$ and $\mathrm{E} / \mathrm{In}$ responses were obtained from units located in both superficial regions and deep DCN. The locations of units with In responses are consistent with the locations of fusiform cells in layer 2 of the guinea pig DCN, whereas the locations of E and E/In units are consistent with those units being both fusiform and giant cells (Hackney et al., 1990). Additional support for this conclusion is provided by the observation that the unit types most likely to respond to trigeminal stimulation in this study were the pauser-buildup or buildup unit type. Both of these unit types have been associated with fusiform cells in layer 2 as well as giant cells in the deeper layers of

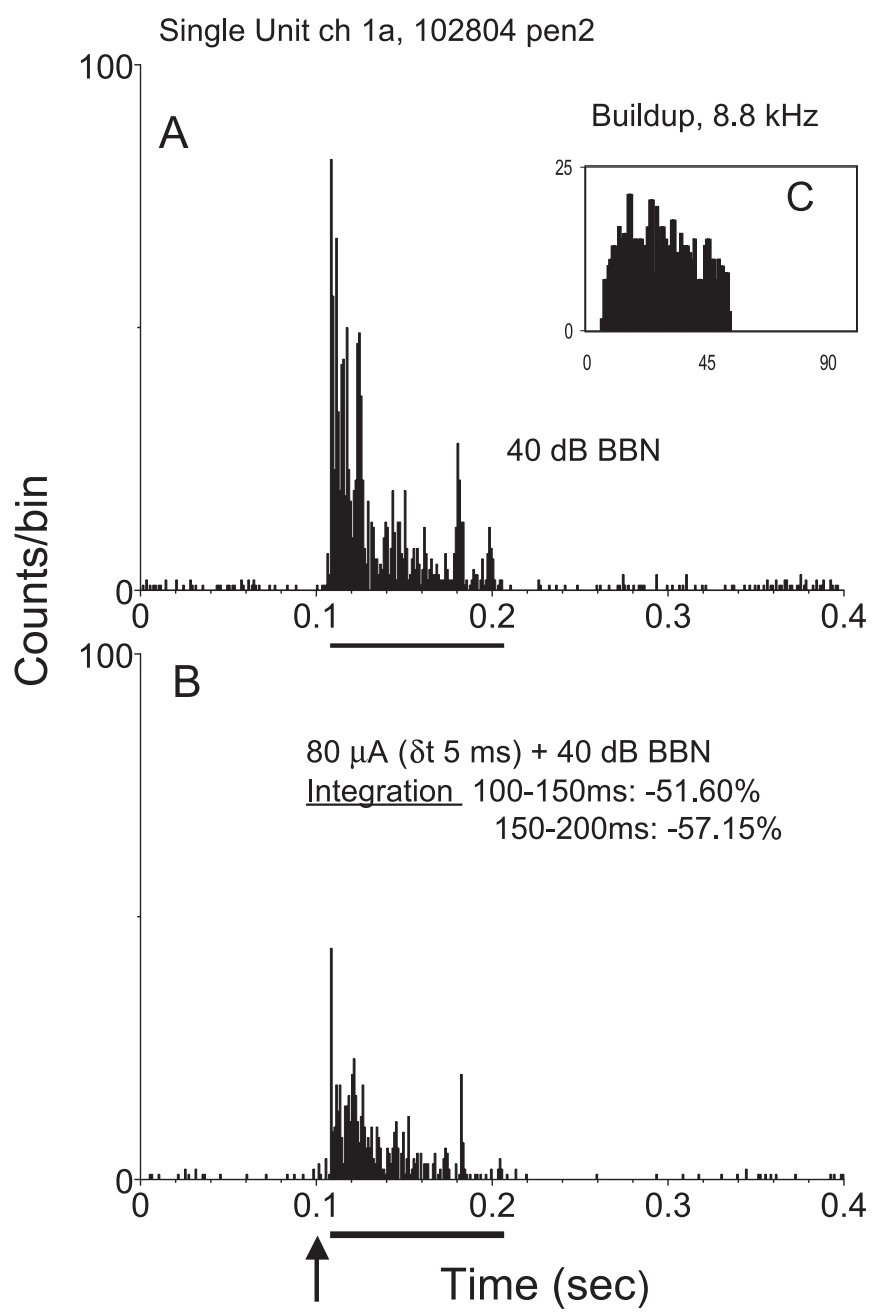

FIG. 7. Trigeminal ganglion stimulation can suppress responses to sound in single units. (A) Unimodal stimulation. Post-stimulus time histogram (PSTH) of responses of an isolated single unit to a broadband noise (BBN) stimulus (40 dB SPL, $100 \mathrm{~ms}$ ). This unit was classified as a buildup unit. (B) Bimodal stimulation. PSTH of responses of the same single unit to the BBN noise stimulus preceded by electrical stimulation of the trigeminal ganglion (onset $5 \mathrm{~ms}$ preceding $\mathrm{BBN}, 80 \mu \mathrm{A}, 100 \mu \mathrm{s} /$ phase). Arrow indicates onset of electrical stimulation at $95 \mathrm{~ms}$; solid bar indicates $100 \mathrm{~ms}$ duration of BBN, 200 presentations. Bin width, $0.5 \mathrm{~ms}$. Multisensory integration to the bimodal stimulus is calculated for times $100-150$ or $150-200 \mathrm{~ms}$. Suppression of more than $50 \%$ occurs for both measures in this unit indicating maximal trigeminal suppression of activity to the BBN at the beginning of the response and continuing throughout its duration. (C) PSTH of the same unit's responses to a 50 -ms, best frequency toneburst, indicating a buildup response pattern. Bin width, $1 \mathrm{~ms} ; 100$ repetitions. Tone onset, $0 \mathrm{~ms}$. $\delta$ t, time between trigeminal stimuli and noise burst; ch, channel.

DCN (Rhode et al., 1983; Joris, 1998; Babalian et al., 2003). Some of these units were also classified as type IV on the basis of their ratelevel responses to BF tones and noise (Young, 1998).

Previous studies have demonstrated that electrical stimulation of second-order somatosensory nuclei, the dorsal column and trigeminal nuclei, produced inhibition, excitation preceding inhibition and excitation in cells in the superficial and deep layers of DCN (Saade et al., 1989; Young et al., 1995; Kanold \& Young, 2001), consistent with the findings presented here. However, in the present study, there was a higher prevalence of $\mathrm{E} / \mathrm{In}$ and $\mathrm{E}$ responses compared with In responses than in the previous studies and a lower percentage of units that responded to the somatosensory stimulation in the absence of 


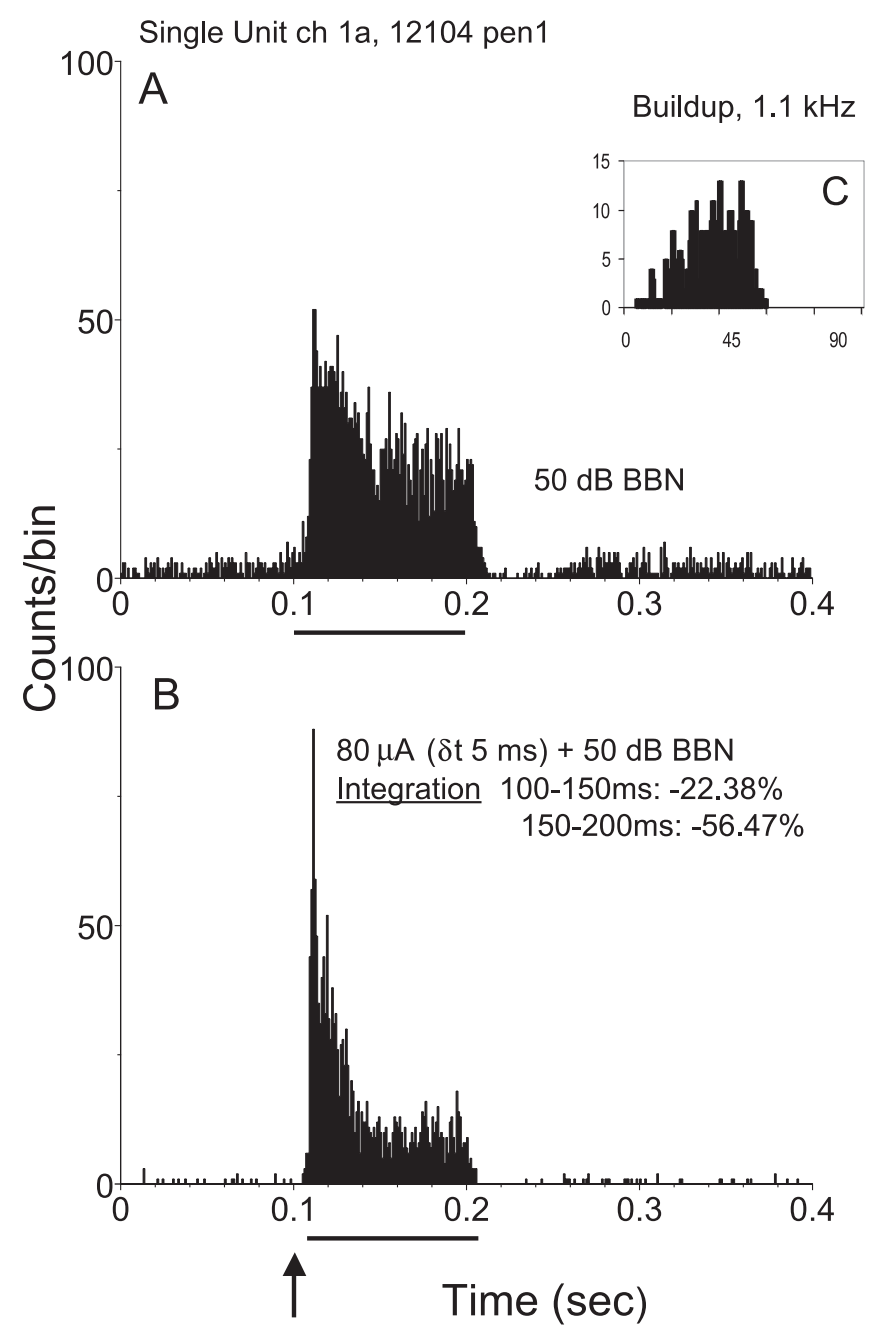

FIG. 8. Trigeminal ganglion stimulation can suppress responses to sound in single units. (A) Unimodal stimulation. Post-stimulus time histogram (PSTH) of responses of an isolated single unit to a broadband noise (BBN) stimulus (50 dB SPL, $100 \mathrm{~ms}$ ). (B) Bimodal stimulation. PSTH of responses of the same single unit to the BBN noise stimulus preceded by electrical stimulation of the trigeminal ganglion (onset $5 \mathrm{~ms}$ preceding BBN; $80 \mu \mathrm{A} ; 100 \mu \mathrm{s} /$ phase). Arrow indicates onset of electrical stimulation at $95 \mathrm{~ms}$; solid bar indicates $100 \mathrm{~ms}$ duration of BBN; 200 presentations. Bin width, $0.5 \mathrm{~ms}$. Multisensory integration to the bimodal stimulus is calculated for times $100-150$ or 150 $200 \mathrm{~ms}$. Suppression of more than $50 \%$ occurs during the period $150-200 \mathrm{~ms}$ but not during the period $100-150 \mathrm{~ms}$ in this unit, indicating a delayed maximal suppression. (C) PSTH of the same unit's responses to a 50 -ms, best frequency toneburst, indicating a buildup response pattern. Bin width, $1 \mathrm{~ms}$; 100 repetitions. Tone onset, $0 \mathrm{~ms}$. $\delta \mathrm{t}$, time between trigeminal stimuli and noise burst.

sound stimulation. One explanation for this discrepancy could be that more units were recorded from the deeper layers of DCN in the present study, as more of the excitatory responses were recorded from deeper layers in the present study and in previous studies (Young et al., 1995). Additionally, the present study exclusively stimulated trigeminal pathways to the $\mathrm{CN}$, whereas the previous studies stimulated a region containing cells in the dorsal column nuclei as well as trigeminal nuclei. An additional consideration is that the number of trials used in this study was lower than that used in the previous studies, yielding a conservative estimate of the number of responsive neurons in the present study.

\section{Single Unit ch 3a, 121004 pen1}

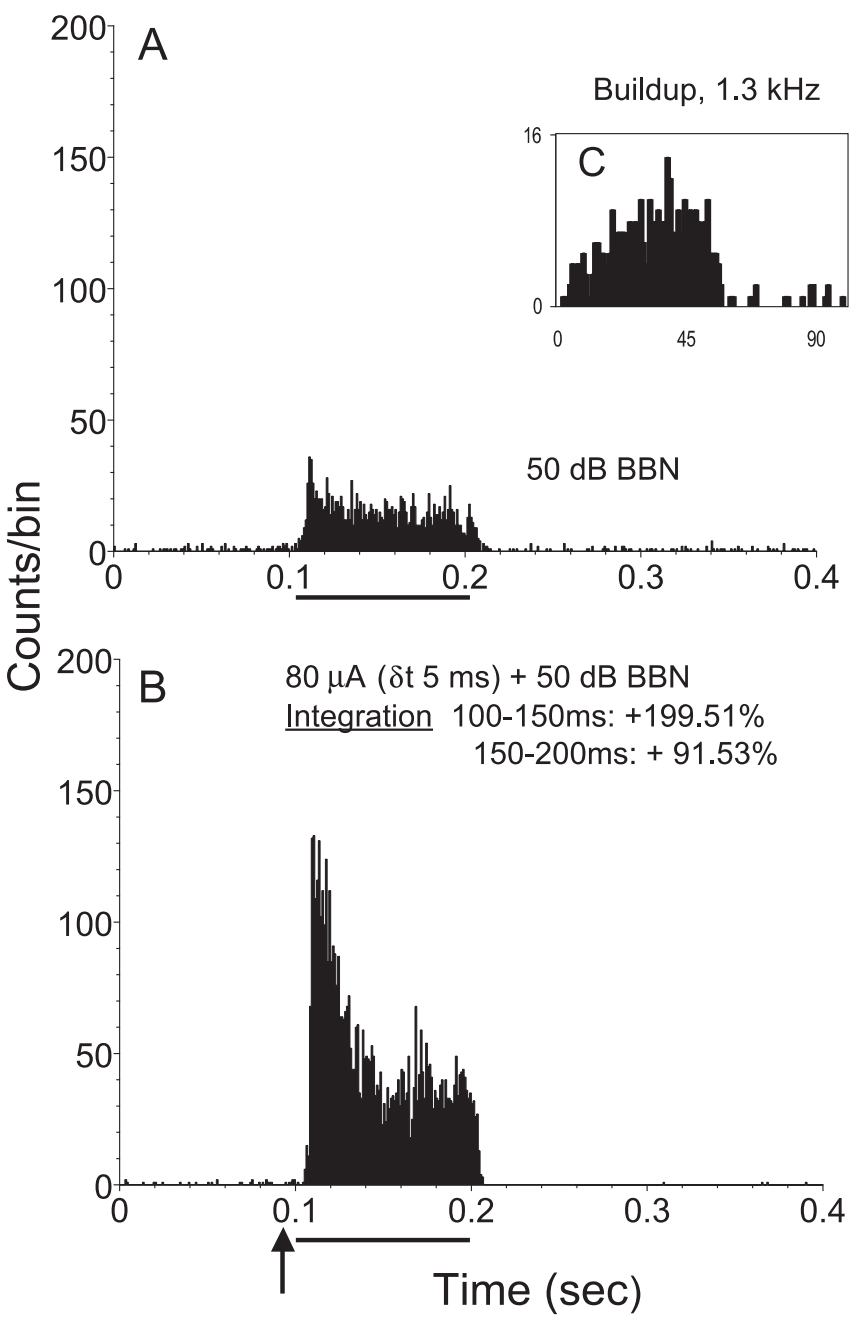

FIG. 9. Trigeminal ganglion stimulation can enhance responses to sound in single units. (A) Unimodal stimulation. Post-stimulus time histogram (PSTH) of responses of an isolated single unit to a broadband noise (BBN) stimulus (50 dB SPL, $100 \mathrm{~ms}$ ). (B) Bimodal stimulation. PSTH of responses of the same single unit to the $\mathrm{BBN}$ noise stimulus preceded by electrical stimulation of the trigeminal ganglion (onset $5 \mathrm{~ms}$ preceding BBN; $80 \mu \mathrm{A} ; 100 \mu \mathrm{s} /$ phase). Arrow indicates onset of electrical stimulation at $95 \mathrm{~ms}$; solid bar indicates 100 -ms duration of BBN; 200 presentations. Bin width, $0.5 \mathrm{~ms}$. Multisensory integration to the bimodal stimulus is calculated for times $100-150$ or 150 $200 \mathrm{~ms}$. Enhancement of almost $200 \%$ occurs during the period $150-200 \mathrm{~ms}$ and enhancement of almost $100 \%$ occurs during the period $100-150 \mathrm{~ms}$ in this unit, indicating a more rapid effect than demonstrated for the suppression in Fig. 7. The enhancement lasts for the duration of the stimulus. (C) PSTH of the same unit's responses to a 50 -ms, best frequency toneburst, indicating a buildup response pattern. Bin width, $1 \mathrm{~ms} ; 100$ repetitions. Tone onset, $0 \mathrm{~ms}$. $\delta$ t, time between trigeminal stimuli and noise burst.

Response latencies for all response types ranged from 5 to $30 \mathrm{~ms}$, with a mean latency around $11 \mathrm{~ms}$, consistent with activation via multiple synapses. The mean latencies, however, were significantly shorter for $\mathrm{E}$ and $\mathrm{E} / \mathrm{In}$ responses than for In responses, by at least $2 \mathrm{~ms}$. These latency differences support the conclusions of previous authors that the excitatory responses to somatosensory stimulation probably reflect the activation of fusiform cells directly through granule cells, whereas inhibitory responses are attributed to modulation via an inhibitory interneuron, the cartwheel cell (Manis et al., 1994; Young et al., 1995; Davis \& Young, 1997). Thus, excitatory 


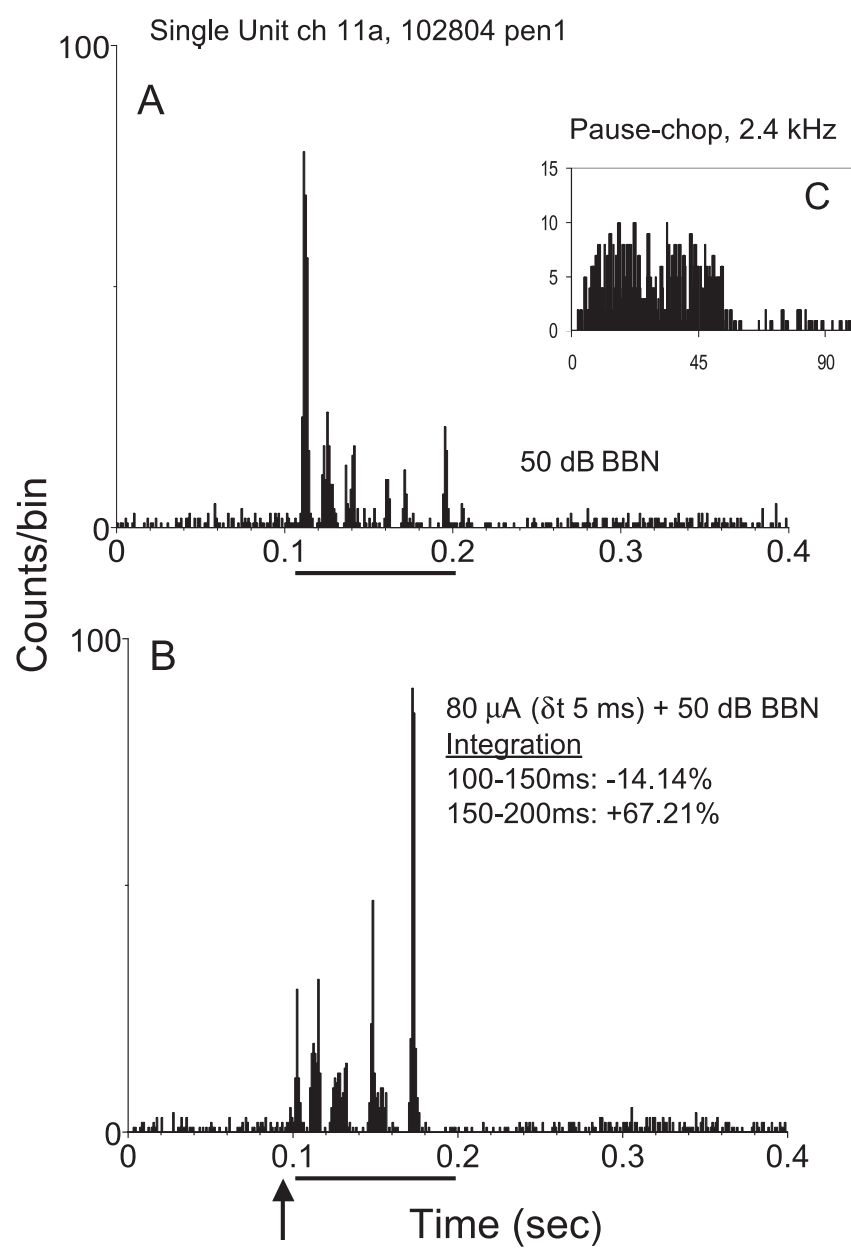

FIG. 10. Trigeminal ganglion stimulation can alter the temporal pattern of single units responses to sound. (A) Unimodal stimulation. Post-stimulus time histogram (PSTH) of responses of an isolated single unit to a broadband noise (BBN) stimulus (50 dB SPL, $100 \mathrm{~ms}$ ). This unit was determined to be a buildup unit. (B) Bimodal stimulation. PSTHs of responses of the same single unit to the BBN noise stimulus preceded by electrical stimulation of the trigeminal ganglion (onset $5 \mathrm{~ms}$ preceding $\mathrm{BBN} ; 80 \mu \mathrm{A} ; 100 \mu \mathrm{s} /$ phase). Arrow indicates onset of electrical stimulation at $95 \mathrm{~ms}$; solid bar indicates $100 \mathrm{~ms}$ duration of BBN; 200 presentations. Bin width, $0.5 \mathrm{~ms}$. Multisensory integration to the bimodal stimulus is calculated for times $100-150$ or 150 $200 \mathrm{~ms}$. Some suppression occurs during the period $150-200 \mathrm{~ms}$ and enhancement of almost $70 \%$ occurs during the period $100-150 \mathrm{~ms}$ in this unit, with the ultimate effect producing a reversal of the temporal pattern evoked by the BBN after trigeminal stimulation. (C) PSTH of the same unit's responses to a $50-\mathrm{ms}$, best frequency toneburst, indicating a pause-chop response pattern. Bin width, $1 \mathrm{~ms} ; 100$ repetitions. Tone onset, $0 \mathrm{~ms}$. $\delta$ t, time between trigeminal stimuli and noise burst.

responses would be expected to have shorter latencies than inhibitory responses. The granule cells themselves are activated by inputs from the trigeminal ganglion or spinal trigeminal nucleus, some of which have mossy fiber type endings (Shore et al., 2000; Zhou \& Shore, 2004; Haenggeli et al., 2005) and are thus expected to have slower activation than direct synapses, consistent with the latencies demonstrated in the present study of greater than $5 \mathrm{~ms}$. The shortest activation would be expected to occur through inputs arising in the trigeminal ganglion, shown to terminate in small cell cap and marginal cell regions of the VCN that contain granule cells (Shore \& Moore, 1998; Shore et al., 2000). The parallel fiber output of these granule cells, in turn, sends an excitatory projection to both fusiform and cartwheel cells in the DCN (Mugnaini et al., 1980a,b). Responses with
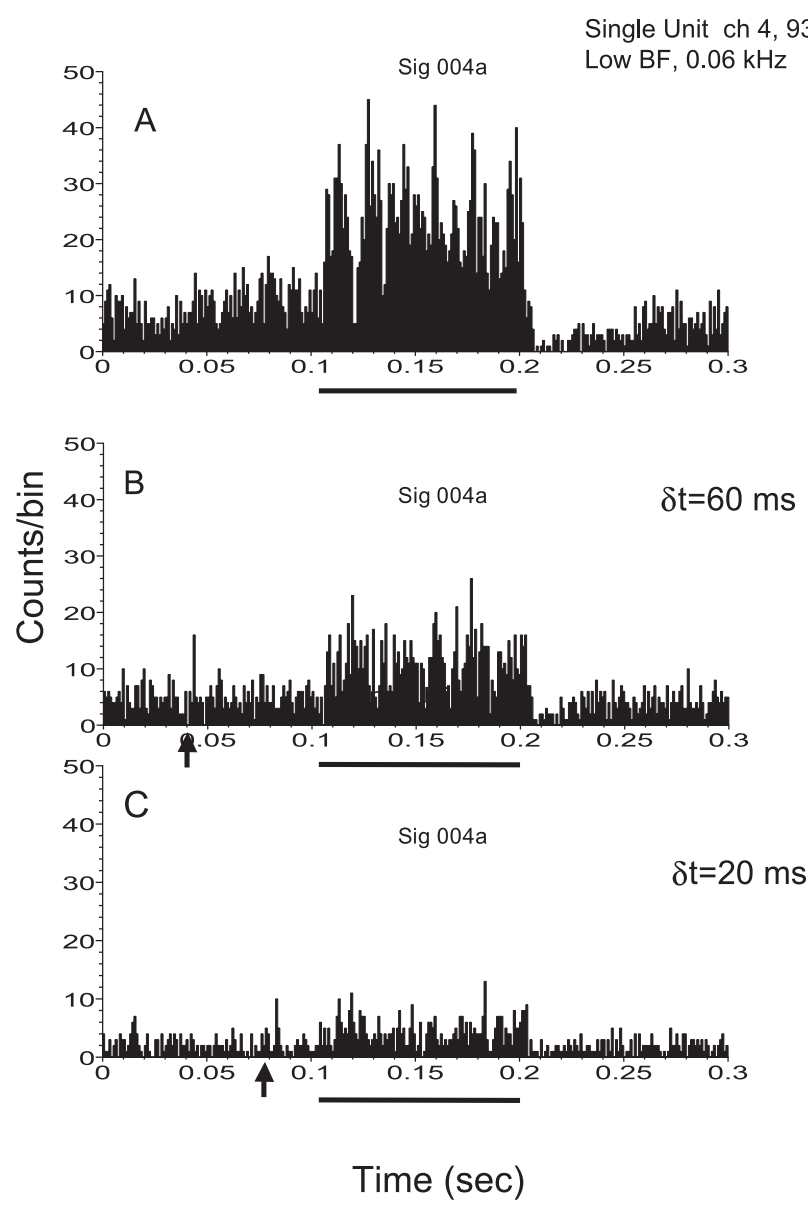

FIG. 11. Trigeminal stimulation differentially suppresses responses to broadband noise $(\mathrm{BBN})$ depending on the temporal gap [ $\delta \mathrm{t}(\mathrm{dt})]$ between the two bimodal stimuli. Post-stimulus time histograms of responses from one single unit to combined trigeminal and acoustic stimulation $(80 \mu \mathrm{A}+30 \mathrm{~dB}$ SPLBBN) are shown. (A) BBN alone; (B) trigeminal stimulation precedes BBN by $60 \mathrm{~ms}$; (C) trigeminal stimulation precedes BBN by $20 \mathrm{~ms}$. Suppression is greatest at small dt values. Arrow shows onset of trigeminal stimulation; bar below PSTH shows onset and duration of BBN. Bin width, $1.0 \mathrm{~ms}$. This low best frequency (BF) unit showed a typical phase-locked response throughout the duration of $\mathrm{BF}$ toneburst stimulation (not shown). $\delta \mathrm{t}$, time between trigeminal stimuli and noise burst.

longer latencies could be attributed to activation via additional interneurons, either in the trigeminal nucleus (Itoh et al., 1987; Zhou $\&$ Shore, 2004) or via higher auditory pathways that receive trigeminal input (Shore et al., 1991; Li \& Mizuno, 1997).

In addition to the granule cell-fusiform cell connection, an additional circuit may exist, in which cells in the deep DCN are activated through synaptic terminals from the spinal trigeminal nucleus in the deep DCN (Zhou \& Shore, 2004) and serve as inhibitory interneurons to fusiform cells. Zhou \& Shore (2004) have indeed demonstrated terminal endings in layer 3 of the DCN, in the vicinity of vertical (also called tuberculoventral) cells after injections of anterograde tracers into the spinal trigeminal nucleus of the guinea pig. Vertical cells, normally excited by VIIIth nerve input, strongly inhibit fusiform cells and may therefore be an alternative explanation for the inhibition observed in response to trigeminal stimulation. Of course, terminals in this region could also directly activate giant cells that reside in layers 3 and 4 of the DCN and provide an alternate route for the excitation observed in buildup units. 

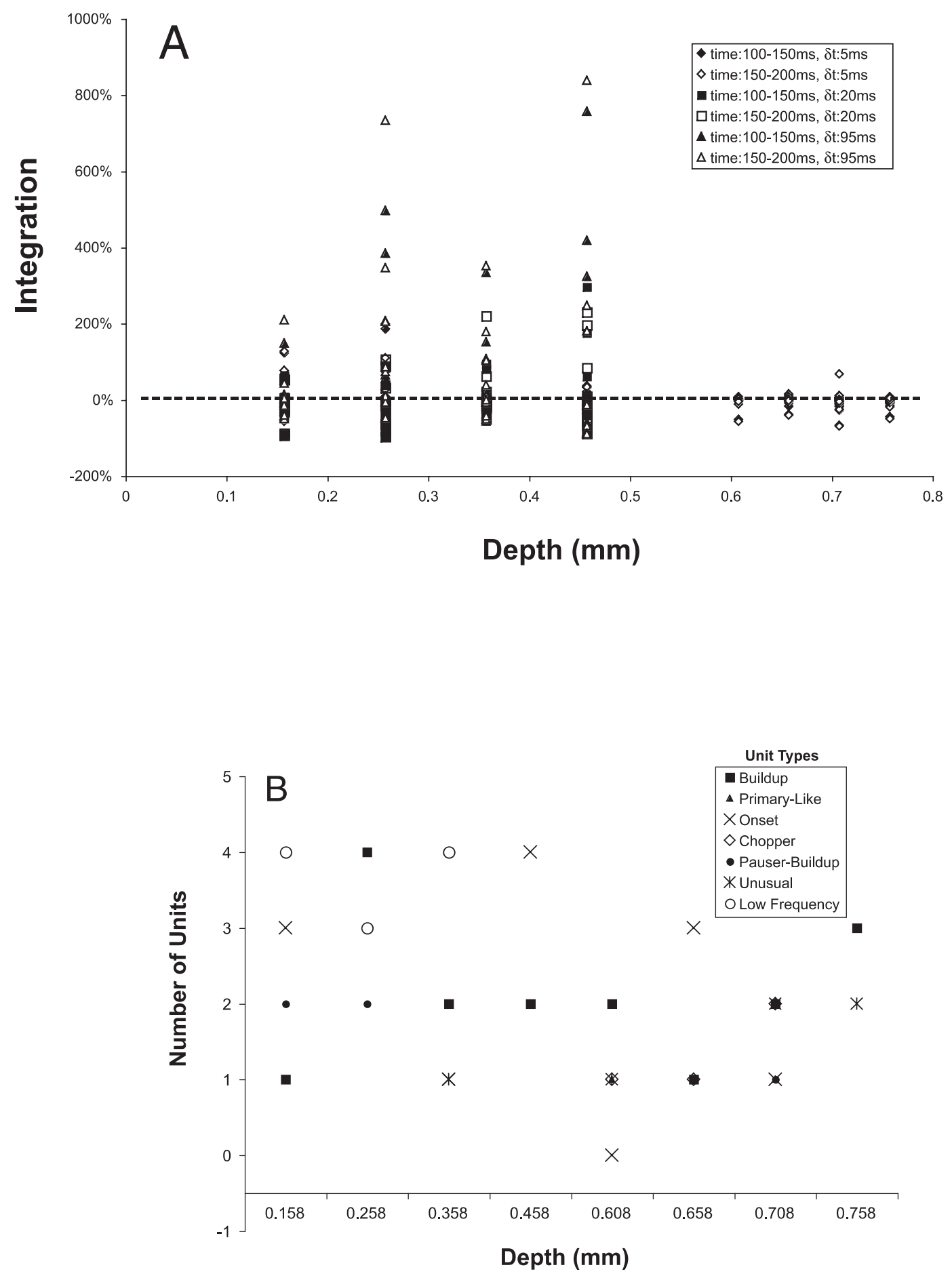

FIG. 12. (A) Summary of integration in single units as a function of their location in the dorsal cochlear nucleus (DCN). Symbols designate the $\delta t$ and time segment across which integration was measured. Units located within $0.5 \mathrm{~mm}$ of the DCN surface showed greater integration than units located deeper than $0.5 \mathrm{~mm}$. Broadband noise ranged from 25 to $60 \mathrm{~dB}$ SPL, trigeminal stimulation was at $80 \mu \mathrm{A}$. (B) Unit types as a function of their location in the DCN are indicated by specific symbols. The predominant types of units integrating trigeminal and acoustic information were buildup and pauser-buildup.

\section{Dorsal cochlear nucleus neurons integrate acoustic and somatosensory stimuli}

Trigeminal ganglion stimulation usually suppresses but can also enhance dorsal cochlear nucleus responses to sound

Multisensory integration occurred in $78 \%$ of neurons tested with bimodal stimulation. When paired with sound stimulation (BBN), trigeminal stimulation suppressed the responses elicited to $\mathrm{BBN}$ stimulation in $60 \%$ and enhanced the responses in $28 \%$ of units tested with bimodal stimulation. This was true whether the response to trigeminal stimulation was excitatory or inhibitory when presented in isolation. In many cases, even when little or no response was evident to trigeminal stimulation alone (with 100 presentations), nonetheless responses to $\mathrm{BBN}$ could be altered, as shown in the greater percentage 


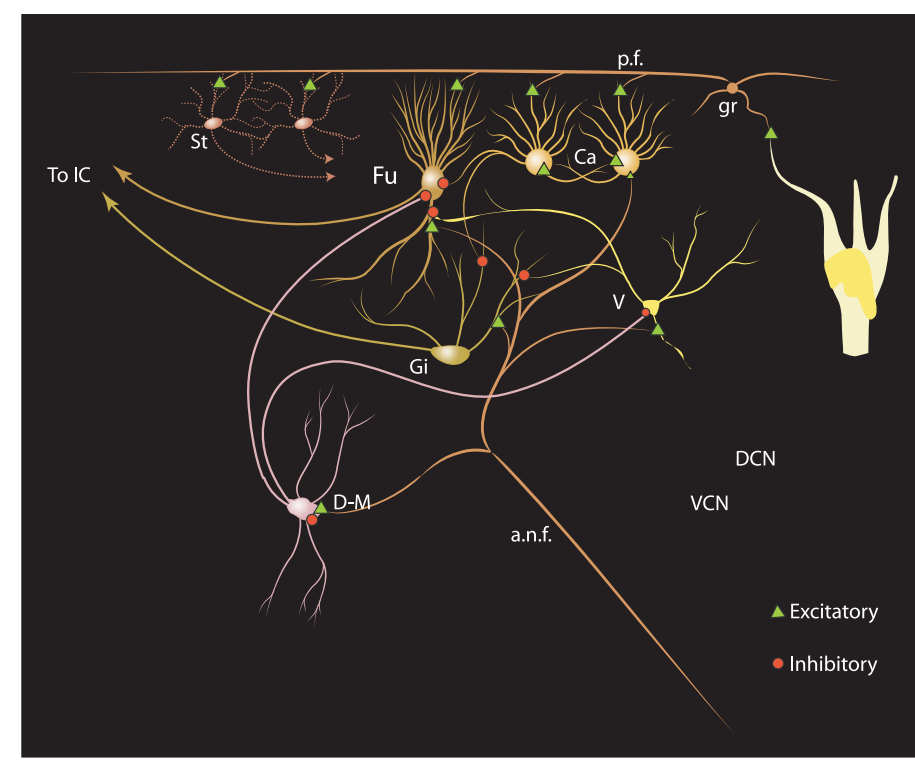

of units affected by bimodal than trigeminal stimulation (see above discussion of unimodal trigeminal responses in the absence of sound). The combined responses to acoustic and trigeminal stimulation exceeded that predicted by linear summation of the responses to unimodal stimulation (enhancement) or were less than the larger of the unimodal responses (suppression) thus fulfillling the criteria for multisensory integration (Stein \& Meredith, 1990; Populin \& Yin, 2002).

The suppressive form of multisensory integration in DCN neurons, whereby stimulation of trigeminal neurons more often suppressed the responses elicited by sound, is unusual. Inputs from one modality have generally been shown to enhance the activity induced by another modality (Brett-Green et al., 2003, 2004). However, a recent report demonstrated multimodal somatosensory-auditory suppression of firing in neurons of the ectosylvian cortex that were not affected by stimulation of either modality alone (Dehner et al., 2004). Neurons in the superior colliculus of the awake, behaving cat were also found to display primarily bimodal depression, in contrast to previous studies indicating primarily enhancement in anesthetized preparations (Populin \& Yin, 2002). In the DCN, multisensory integration may be facilitated by the adjustability of synapses between parallel fibers and their targets, the fusiform, giant and cartwheel cells (Fujino \& Oertel, 2003; Tzounopoulos et al., 2004). In those studies, postsynaptic depolarization (analogous to our sound stimulation) preceded by stimulation of parallel fibers (analogous to trigeminal stimulation) produced long-term depression or potentiation in fusiform or giant cells (analogous to our depression and sometimes facilitation of responses to sound). This could explain why multisensory integration can be both suppressive and facilitative in the DCN. The suppressive/facilitative effects in our study could last up to $90 \mathrm{~ms}$ when the stimuli were separated by gaps but could last the duration of the acoustic stimulus (up to $200 \mathrm{~ms}$ ) when bimodal stimuli were presented simultaneously.

Figure 13 shows the proposed circuitry for multisensory integration in the DCN. Trigeminal ganglion stimulation activates granule cells that excite the principal output neurons of the $\mathrm{DCN}$, fusiform or giant cells, as well as inhibitory interneurons, the cartwheel cells (Golding \& Oertel, 1997). Cartwheel cells, in turn, inhibit principal cells (Davis et al., 1996). BBN (via auditory nerve fibres) strongly activates principal cells (Stabler et al., 1996; Young, 1998) and weakly activates
FIG. 13. Schematic of dorsal cochlear nucleus (DCN) circuitry putatively involved in multisensory integration (after Young, 1998). Trigeminal ganglion (TG) stimulation activates granule cells (gr) that excite cartwheel $(\mathrm{Ca})$ and fusiform $(\mathrm{Fu})$ or giant (Gi) cells. Ca cells inhibit Fu cells. Broadband noise $(\mathrm{BBN})$ excites Fu cells and weakly activates $\mathrm{Ca}$ cells. Inhibition of responses to $\mathrm{BBN}$ is achieved by summation of weak Ca responses to $\mathrm{BBN}$ and stronger and long-lasting $\mathrm{Ca}$ activation by trigeminal input, leading to inhibition of $\mathrm{Fu}$ cells. Facilitation of BBN responses can occur through long-term potentiation of gr activation of Fu cells. Additionally, TG stimulation may excite onset units in ventral cochlear nucleus (VCN) [D-multipolar cells which can inhibit vertical (V) and Fu cells] (see text for details). Abbreviations: a.n.f., auditory nerve fiber; D-M, D-Multipolar cell; IC, inferior colliculus; p.f., parallel fiber; St, stellate cell.

some cartwheel cells (Parham \& Kim, 1995). Multisensory integration that suppresses responses of principal cells to BBN could be achieved by summation of weak cartwheel responses to $\mathrm{BBN}$ and stronger cartwheel cell activation by trigeminal input, leading to inhibition of the principal cell response to BBN. Similarly, facilitation of BBN responses could occur through summation of granule cell-fusiform/giant cell activation by BBN and trigeminal input. The longlasting effect of this suppression or facilitation could be related to membrane properties of fusiform cells that have been demonstrated to depend on prior activity or 'history' (Manis, 1990). Indeed, membrane depolarization has been shown to increase the duration of an excitatory post-synaptic potential (Hirsch \& Oertel, 1988). An alternative mechanism of suppressive integration could be through activation of onset units in the VCN by trigeminal stimulation (Shore et al., 2003), some of which may be D-multipolar cells (On-chopper cells) which can inhibit vertical and fusiform cells (Spirou et al., 1999; Arnott et al., 2004).

Based on findings that stimulation of pinna regions in cats produced stronger responses in DCN than stimulation of other areas of the face, Young and colleagues have convincingly suggested that dorsal column nuclear input to the DCN may be involved with sound localization which, in the cat, is aided by the mobility of the pinna (Young et al., 1995; Davis et al., 1996; Kanold \& Young, 2001). However, the guinea pig and other rodents do not move their pinnas to aid in sound localization and nor do many other mammals.

Our study provides evidence that the DCN may not only be involved in localization but may also act as an adaptive filter to reduce body-generated sounds. The present study is the first to combine activation of trigeminal inputs to the $\mathrm{CN}$ with sound stimulation. This would simulate a natural condition in which the $\mathrm{CN}$ would receive simultaneous auditory and somatosensory inputs, as in chewing, respiration and self-vocalization. This study revealed that trigeminal stimulation strongly suppressed sound-evoked activity and even reversed the temporal firing pattern evoked by a noise stimulus after the addition of a trigeminal stimulus (Fig. 10). These findings are consistent with the behavior of other cerebellar-like systems, with granule cell-parallel fiber circuits, canceling out unwanted stimulation produced by the animal's own movements. For example, in the electrosensory lateral line of weakly electric fish, electric fields generated by the animal's own respiration are cancelled 
out in principal cells by motor and proprioceptive information carried via the parallel pathways that are analogous to those seen in the mammalian DCN (Montgomery \& Bodznick, 1994; Bell et al., 1997). Thus, we propose that an additional function of the parallel fiber inputs to the DCN, arising in the trigeminal system, is to suppress internally generated sounds produced by chewing, respiration and self-vocalization. These combined acoustic-somatosensory activations would occur every time an animal performed these movements.

The multisensory integration demonstrated in the present study, in which trigeminal input enhances the responses of DCN units to noise (see Fig. 9), may be important in improving signal-to-noise ratios when attention is directed to a particular location (Young et al., 1995; Kanold \& Young, 2001). Thus, the DCN could act as an 'adaptive filter' to suppress self-generated sounds but enhance perception of behaviorally relevant sounds, such as the vocalizations of other animals, generated externally and not combined with internal somatosensory stimulation.

The anatomical substrates for this hypothesis include evidence that several trigeminal sensory brainstem subdivisions receive proprioceptive inputs from vocal structures. For example, primary afferent neurons innervating the tongue muscles project to the caudal principal nucleus, Sp5I and Sp5C, in cat (Nazruddin et al., 1989) which, in turn, projects to the CN (Zhou \& Shore, 2004). In addition, the temporomandibular joint and non-encapsulated tongue muscle fibers are innervated by cells in the mandibular region of the trigeminal ganglion (Romfh et al., 1979; Capra, 1987; Suemune et al., 1992). Additional support is provided in reports of the suppression of responses in neurons of the external nucleus of the inferior colliculus in response to self-generated vocalizations but excitation in response to externally generated vocalizations (Tammer et al., 2004). As the DCN projects to the inferior colliculus (Ryugo et al., 1981; Willard \& Martin, 1983; Coleman \& Clerici, 1987; also J. Zhou and S. Shore, unpublished results), these responses could be, at least in part, a reflection of the integration occurring in the DCN.

\section{Clinical implications}

Pathological changes in innervation from peripheral somatosensory structures could also influence auditory functions requiring multisensory input, such as the localization of the body in space, suppression of body-generated sounds or feedback from vocal tract structures to auditory nuclei. Trigeminal input to the DCN could have a significant impact on the response characteristics of higher order neurons that receive its output. Reduction in auditory input to the $\mathrm{CN}$ occurring with deafness necessarily affects the balance of inputs from auditory and somatosensory structures, probably affecting multisensory integration and imparting greater strength to the somatosensory inputs. The multisensory integration demonstrated in this study could be involved in plastic changes in the brain which may lead to perceptions of phantom sounds ('tinnitus') in the absence of physical sound. The majority of patients are able to modify their tinnitus by manipulations of somatic regions of the head and neck ('somatic tinnitus'), such as jaw clenching (Levine, 1999b; Levine et al., 2003; Abel \& Levine, 2004). Other patients experience the perception of tinnitus after receiving somatic insults such as neck injuries or tooth abscess (Lockwood et al., 1998; Pinchoff et al., 1998; Levine, 1999a). These phantom perceptions could be a result of disrupted or altered somatosensory input to the $\mathrm{CN}$. Learning more about the anatomy and physiology of these interactions could lead to future interventions to provide relief to patients with somatic tinnitus.

\section{Acknowledgements}

I am grateful to Jianzhong $\mathrm{Lu}$ and Seth Koehler for expert technical assistance, Jianxun Zhou and Mazy Bissinger for histological reconstructions and Chris Ellinger for invaluable electronic assistance. Discussions with Drs Paul Manis, Sanford Bledsoe and Sarah Newman were helpful in interpreting the results. The Center for Neural Communication Technology in the Department of Engineering supplied the multichannel electrodes. This work was supported by grants from the NIH (R01 DC004825), core center grant P30 DC-05188 and the Tinnitus Research Consortium.

\section{Abbreviations}

$\mathrm{BBN}$, broadband noise; $\mathrm{BF}$, best frequency; $\mathrm{CN}$, cochlear nucleus; $\delta$ t, time between trigeminal stimuli and noise burst; DCN, dorsal cochlear nucleus; E units, units showing excitation to trigeminal stimulation; E/In units, units showing excitation then inhibition after trigeminal stimulation; In units, units showing inhibition to trigeminal stimulation; PSTH, post-stimulus time histograms; VCN, ventral cochlear nucleus.

\section{References}

Abel, M.D. \& Levine, R.A. (2004) Muscle contractions and auditory perception in tinnitus patients and nonclinical subjects. Cranio, 22, 181-191.

Adams, J.C. \& Warr, W.B. (1976) Origins of axons in the cat's acoustic striae determined by injection of horseradish peroxidase into severed tracts. J. Comp. Neurol., 170, 107-121.

Arnott, R.H., Wallace, M.N., Shackleton, T.M. \& Palmer, A.R. (2004) Onset neurones in the anteroventral cochlear nucleus project to the dorsal cochlear nucleus. J. Assoc. Res. Otolaryngol., 5, 153-170.

Babalian, A.L., Ryugo, D.K. \& Rouiller, E.M. (2003) Discharge properties of identified cochlear nucleus neurons and auditory nerve fibers in response to repetitive electrical stimulation of the auditory nerve. Exp. Brain Res., 153, 452-460.

Bell, C., Bodznick, D., Montgomery, J. \& Bastian, J. (1997) The generation and subtraction of sensory expectations within cerebellum-like structures. Brain Behav. Evol., 50 (Suppl. 1), 17-31.

Brett-Green, B., Fifkova, E., Larue, D.T., Winer, J.A. \& Barth, D.S. (2003) A multisensory zone in rat parietotemporal cortex: intra- and extracellular physiology and thalamocortical connections. J. Comp. Neurol., 460, 223-237.

Brett-Green, B., Paulsen, M., Staba, R.J., Fifkova, E. \& Barth, D.S. (2004) Two distinct regions of secondary somatosensory cortex in the rat: topographical organization and multisensory responses. J. Neurophysiol., 91, 1327-1336.

Capra, N.F. (1987) Localization and central projections of primary afferent neurons that innervate the temporomandibular joint in cats. Somatosens. Res., 4, 201-213.

Coleman, J.R. \& Clerici, W.J. (1987) Sources of projections to subdivisions of the inferior colliculus in the rat. J. Comp. Neurol., 262, 215-226.

Covey, E., Jones, D. \& Casseday, J. (1984) Projections from the superior olivary complex to the cochlear nucleus in the tree shrew. J. Comp. Neurol., 226, 289-305.

Davis, K. \& Young, E. (1997) Granule cell activation of complex-spiking neurons in dorsal cochlear nucleus. J. Neurosci., 17, 6798-6806.

Davis, K.A., Miller, R.L. \& Young, E.D. (1996) Effects of somatosensory and parallel-fiber stimulation on neurons in dorsal cochlear nucleus. J. Neurophysiol., 76, 3012-3024.

Dehner, L.R., Keniston, L.P., Clemo, H.R. \& Meredith, M.A. (2004) Crossmodal circuitry between auditory and somatosensory areas of the cat anterior ectosylvian sulcal cortex: a 'new' inhibitory form of multisensory convergence. Cereb. Cortex, 14, 387-403.

Fujino, K. \& Oertel, D. (2003) Bidirectional synaptic plasticity in the cerebellum-like mammalian dorsal cochlear nucleus. PNAS, 100, 265-270.

Godfrey, D., Kiang, N. \& Norris, B. (1975a) Single unit activity in the posteroventral cochlear nucleus of the cat. J. Comp. Neurol., 162, 247-268.

Godfrey, D.A., Kiang, N.Y. \& Norris, B.E. (1975b) Single unit activity in the dorsal cochlear nucleus of the cat. J. Comp. Neurol., 162, 269-284.

Golding, N.L. \& Oertel, D. (1997) Physiological identification of the targets of cartwheel cells in the dorsal cochlear nucleus. J. Neurophysiol., 78, 248-260.

Hackney, C.M., Osen, K.K. \& Kolston, J. (1990) Anatomy of the cochlear nuclear complex of guinea pig. Anat. Embryol. (Berl.), 182, 123-149.

Haenggeli, C.A., Pongstaporn, T., Doucet, J.R. \& Ryugo, D.K. (2005) Projections from the spinal trigeminal nucleus to the cochlear nucleus in the rat. J. Comp. Neurol., 484, 191-205. 
Hirsch, J.A. \& Oertel, D. (1988) Synaptic connections in the dorsal cochlear nucleus of mice, in vitro. J. Physiol. (Lond.), 396, 549-562.

Itoh, K., Kamiya, H., Mitani, A., Yasui, Y., Takada, M. \& Mizuno, N. (1987) Direct projections from the dorsal column nuclei and the spinal trigeminal nuclei to the cochlear nuclei in the cat. Brain Res., 400, 145-150.

Joris, P.X. (1998) Response classes in the dorsal cochlear nucleus and its output tract in the chloralose-anesthetized cat. J. Neurosci., 18, 3955-3966.

Kanold, P.O. \& Young, E.D. (2001) Proprioceptive information from the pinna provides somatosensory input to cat dorsal cochlear nucleus. J. Neurosci., 21, 7848-7858.

Le Prell, C.G., Shore, S.E., Hughes, L.F. \& Bledsoe, S.C. Jr (2003) Disruption of lateral efferent pathways: functional changes in auditory evoked responses. J. Assoc. Res. Otolaryngol., 4, 276-290.

Levine, R. (1999a) Somatic modulation of Tinnitus appears to be a fundamental attribute of tinnitus. Proc. 6th Int. Tinnitus Seminar, Cambridge, UK, 1, 93197.

Levine, R.A. (1999b) Somatic (craniocervical) tinnitus and the dorsal cochlear nucleus hypothesis. Am. J. Otolaryngol., 20, 351-362.

Levine, R.A., Abel, M. \& Cheng, H. (2003) CNS somatosensory-auditory interactions elicit or modulate tinnitus. Exp. Brain Res., 153, 643-648.

Li, H. \& Mizuno, N. (1997) Single neurons in the spinal trigeminal and dorsal column nuclei project to both the cochlear nucleus and the inferior colliculus by way of axon collaterals: a fluorescent retrograde double-labeling study in the rat. Neurosci. Res., 29, 135-142.

Lockwood, A., Salvi, R., Ciad, B., Towsley, M., Wack, M. \& Murphy, M. (1998) The functional neuroanatomy of tinnitus: Evidence for limbic system links and neural plasticity. Neurology, 50, 114-120.

Manis, P.B. (1990) Membrane properties and discharge characteristics of guinea pig dorsal cochlear nucleus neurons studied in vitro. J. Neurosci., 10, $2338-2351$.

Manis, P.B., Spirou, G.A., Wright, D.D., Paydar, S. \& Ryugo, D.K. (1994) Physiology and morphology of complex spiking neurons in the guinea pig dorsal cochlear nucleus. J. Comp. Neurol., 348, 261-276.

Montgomery, J.C. \& Bodznick, D. (1994) An adaptive filter that cancels selfinduced noise in the electrosensory and lateral line mechanosensory systems of fish. Neurosci. Lett., 174, 145-148.

Mugnaini, E., Warr, W.B. \& Osen, K.K. (1980a) Distribution and light microscopic features of granule cells in the cochlear nuclei of cat, rat, and mouse. J. Comp. Neurol., 191, 581-606.

Mugnaini, E., Osen, K.K., Dahl, A.L., Friedrich, V.L. Jr \& Korte, G. (1980b) Fine structure of granule cells and related interneurons (termed Golgi cells) in the cochlear nuclear complex of cat, rat and mouse. J. Neurocytol., 9, 537570 .

Nazruddin, Suemune, S., Shirana, Y., Yamauchi, K. \& Shigenaga, Y. (1989) The cells of origin of the hypoglossal afferent nerves and central projections in the cat. Brain Res., 490, 219-235.

Parham, K. \& Kim, D.O. (1995) Spontaneous and sound-evoked discharge characteristics of complex-spiking neurons in the dorsal cochlear nucleus of the unanesthetized decerebrate cat. J. Neurophysiol., 73, 550-561.

Pinchoff, R., Burkard, R., Salvi, R., Coad, M. \& Lockwood, A. (1998) Modulation of tinnitus by voluntary jaw movements. Am. J. Otol., 19, 785789

Populin, L.C. \& Yin, T.C.T. (2002) Bimodal interactions in the superior colliculus of the behaving cat. J. Neurosci., 22, 2826-2834.

Rhode, W. \& Smith, P. (1986) Encoding timing and intensity in the ventral cochlear nucleus of the cat. J. Neurophysiol., 56, 261-286.

Rhode, W.S., Smith, P.H. \& Oertel, D. (1983) Physiological response properties of cells labeled intracellularly with horseradish peroxidase in cat dorsal cochlear nucleus. J. Comp. Neurol., 213, 426-447.

Romfh, J.H., Capra, N.F. \& Gatipon, G.B. (1979) Trigeminal nerve and temporomandibular joint of the cat: a horseradish peroxidase study. Exp. Neurol., 65, 99-106.

Ryugo, D.K., Willard, F.H. \& Fekete, D.M. (1981) Differential afferent projections to the inferior colliculus from the cochlear nucleus in the albino mouse. Brain Res., 210, 342-349.

Saade, N., Frangieh, A., Atweh, S. \& Jabbur, S. (1989) Dorsal column input to cochlear neurons in decerebrate-decerebellate cats. Brain Res., 486, 399 402.
Salar, G., Ori, C., Lob, I., Costella, G., Battaggia, C. \& Peserico, L. (1992) Cerebral blood flow changes induced by electrical stimulation of Gassarian ganglion after experimentally induced subarachnoid haemorhage in pigs. Acta Neurochir. Wien, 119, 115-120.

Schofield, B.R. \& Cant, N.B. (1999) Descending auditory pathways: projections from the inferior colliculus contact superior olivary cells that project bilaterally to the cochlear nuclei. J. Comp. Neurol., 409, 210 223.

Shore, S., Helfert, R., Bledsoe, S.J., Altschuler, R. \& Godfrey, D. (1991) Descending projections to the guinea pig cochlear nucleus. Hearing Res., 52 , 255-268.

Shore, S., Vass, Z., Wys, N. \& Altschuler, R. (2000) The trigeminal ganglion innervates the auditory brainstem. J. Comp. Neurol., 419, 271-285.

Shore, S., El-Kashlan, H.K. \& Lu, J. (2003) Effects of trigeminal ganglion stimulation on unit activity of ventral cochlear nucleus neurons. $\mathrm{Neu}$ roscience, 119, 1085-1101.

Shore, S.E. \& Moore, J.K. (1998) Sources of input to the cochlear granule cell region in the guinea pig. Hearing Res., 116, 33-42.

Shore, S.E., Godfrey, D.A., Helfert, R.H., Altschuler, R.A. \& Bledsoe, S.C. Jr (1992) Connections between the cochlear nuclei in guinea pig. Hearing Res., 62, 16-26.

Spangler, K. \& Warr, W. (1991) The Descending Auditory System. Raven Press, New York.

Spangler, K., Cant, N., Henkel, C., Farley, G. \& Warr, W. (1987) Descending projections from the superior olivary complex to the cochlear nucleus of the cat. J. Comp. Neurol., 259, 452-465.

Spirou, G.A., Davis, K.A., Nelken, I. \& Young, E.D. (1999) Spectral integration by type II interneurons in dorsal cochlear nucleus. J. Neurophysiol., 82, 648-663.

Stabler, S.E., Palmer, A.R. \& Winter, I.M. (1996) Temporal and mean rate discharge patterns of single units in the dorsal cochlear nucleus of the anesthetized guinea pig. J. Neurophysiol., 76, 1667-1688.

Stein, B.E. \& Meredith, M.A. (1990) Multisensory integration. Neural and behavioral solutions for dealing with stimuli from different sensory modalities. Ann. N.Y. Acad. Sci., 608, 51-65; discussion 65-70.

Suemune, S., Nishimori, T., Hosoi, M., Suzuki, Y., Tsuru, H., Kawata, T., Yamauchi, K. \& Maeda, N. (1992) Trigeminal nerve endings of lingual mucosa and musculature of the rat. Brain Res., 586, 162-165.

Tammer, R., Ehrenreich, L. \& Jurgens, U. (2004) Telemetrically recorded neuronal activity in the inferior colliculus and bordering tegmentum during vocal communication in squirrel monkeys (Saimiri sciureus). Behav. Brain Res., 151, 331-336.

Tzounopoulos, T., Kim, Y., Oertel, D. \& Trussell, L.O. (2004) Cell-specific, spike timing-dependent plasticities in the dorsal cochlear nucleus. Nat. Neurosci., 7, 719-725.

Vass, Z., Shore, S., Nuttall, A. \& Miller, J. (1998) Direct evidence of trigeminal innervation of the cochlear blood vessels. Neuroscience, 84, 559-567.

Weedman, D. \& Ryugo, D. (1996) Projections from auditory cortex to the cochlear nucleus in rats: synapses on granule cell dendrites. J. Comp. Neurol., 371, 311-324.

Weinberg, R.J. \& Rustioni, A. (1987) A cuneocochlear pathway in the rat. Neuroscience, 20, 209-219.

Willard, F.H. \& Martin, G.F. (1983) The auditory brainstem nuclei and some of their projections to the inferior colliculus in the North American opossum. Neuroscience, 10, 1203-1232.

Winter, I., Robertson, D. \& Cole, K. (1989) Descending projections from auditory brainstem nuclei to the cochlea and cochlear nucleus of the guinea pig. J. Comp. Neurol., 280, 143-157.

Wright, D.D. \& Ryugo, D.K. (1996) Mossy fiber projections from the cuneate nucleus to the cochlear nucleus in the rat. J. Comp. Neurol., 365, $159-172$.

Young, E. (1998) Cochlear nucleus. In Shepherd, G. (Ed.), The Synaptic Organization of the Brain. Oxford University Press, Oxford, pp. 121-158.

Young, E.D., Nelken, I. \& Conley, R.A. (1995) Somatosensory effects on neurons in dorsal cochlear nucleus. J. Neurophysiol., 73, 743-765.

Zhou, J. \& Shore, S. (2004) Projections from the trigeminal nuclear complex to the cochlear nuclei: a retrograde and anterograde tracing study in the guinea pig. J. Neurosci. Res., 78, 901-907. 